\title{
Assessment of SMC Frames under Different Column Removal Scenarios
}

\author{
Mariam Ehab ${ }^{a^{*}}$, Mina Maxi ${ }^{\text {a }}$ \\ ${ }^{a}$ Civil Engineering Department, The British University in Egypt, El Sherouk City, Suez Desert Road, Cairo 11837 - P.O. Box, Egypt.
}

Received 01 October 2019; Accepted 28 December 2019

\begin{abstract}
Throughout the past decades, failure of structures threatening the lives of humans had been popular whether through structure failure due to human error such as Hyatt Regency walkway collapse, 1981, terrorist attacks on the American embassy attack in Nairobi, Kenya 1998 and the famous 9/11 attacks in 2001 and many more. As a result of these incidents, The Unified Facilities Criteria (UFC) was developed concerning the progressive collapse issues by analyzing different types of structures under column loss and studying the overall structural behavior. However, the (UFC) didn't scope on the local behavior of the structural components and its connection under column loss. In this research, the main objective is to study the local behavior of the special moment frame connection (SMC) under column loss. A detailed study is conducted on a 3D model fully designed by adopting the strong-column weak-beam approach following the ACI318-14 regulations. Two frames are selected from the designed structure, interior and exterior frames, to apply the column loss scenario in different locations and different floor levels. The Applied Element Method is adopted in the study. Non-linear time-dependent dynamic analysis is implemented to apply the different column removal scenarios. Twelve case studies are modeled in detail using the Extreme Loading for Structures (ELS) software at which all elements are modeled and analyzed in a 3D model technique. After analyzing the different case studies, structure behavior is observed. Some cases encountered total collapse, other cases encountered partial /local collapse and finally, some survived the column loss scenario. Many parameters are involved and studied in the research. Failure pattern is observed for collapsed cases, the cause of failure is monitored and studied. Special moment connection behavior is studied concerning the shear connection capacity. The location of the column removal with the type of frame selected played an important role in changing the structural behavior from one case to another. As a result, it is not applicable to assume that due to the special moment connection ductility, the structure will be able to resist the column loss in all cases.
\end{abstract}

Keywords: Special Moment Connections; Column Loss; Connection Failure Pattern; Ductile RC Frames; Applied Element Method.

\section{Introduction}

For the past few years, the progressive collapse of structures took place as a result of losing many lives. This led to many codes and parties to study the Progressive Collapse of the structures and set many regulations either to resist it or to restrict its effect on some parts of the buildings. Progressive collapse can take place due to losing one of the main elements either due to terrorist attack, blasting or structural overloading. Regulations that are set to resist the progressive collapse of structures concentrated on the overall structural behavior and how to bridge the failed element and redistribute the loads on the surrounded elements regardless of the structural system used or the type of connections involved in the study. As a result, it is essential to consider the structure system as a main parameter in affecting the

\footnotetext{
* Corresponding author: mariam.ehab@bue.edu.eg
}

http://dx.doi.org/10.28991/cej-2020-03091471

(C) 2019 by the authors. Licensee C.E.J, Tehran, Iran. This article is an open access article distributed under the terms and conditions of the Creative Commons Attribution (CC-BY) license (http://creativecommons.org/licenses/by/4.0/). 
structural behavior due to column loss. Ductile Special moment frame connections are one of the primary systems used in resisting earthquake loading due to its ductility and redundancy.

Many experimental research approaches are conducted to study the structural behavior under different column loss scenarios, mostly for steel frames and connections. Few experimental kinds of research are performed for reinforced concrete frame connections due to the limitations that face the experimental testing such as; the specimen size, column removal scenario simulation and finally the accuracy of the results measured from the failed specimen. The numerical analysis took place and validated by experimental testing to find the most suitable way to investigate the structural behavior due to progressive collapse without the experimental limitations.

Guo et al. [1] observed the behavior of the semi-rigid steel connection under a single column removal scenario; experimental examination took place with a pseudo-static test of a composite frame with flush-endplate connections under the loss of middle column is carried out. He compared the experimental testing with a Finite Element Method (FEM) model subject field using both 3D and 2D components. The properties of bolts affected the progressive collapse through the analytical study conducted. They suggested to improve the behavior of connection in resisting progressive collapse. Li and Sasani [2] evaluated the effects of seismic design in reinforced concrete frame structures and its effect in resisting Progressive collapse. The main parameter in the study is the span length and its response under column removal scenario. They focused on shorter span's buildings at medium seismic activity sites, and taking the effect of the joist torsional stiffness and concrete tensile strength into consideration. The study is implemented using an equivalent single degree of freedom systems to evaluate the maximum displacement response of structures after element failure. It is concluded that the shear resistance of Special frame beams is higher than that of ordinary beams. Weng et al. [3], observed the damage assessment criterion and a conducted an experimental testing on a three-scaled moment-resisting $\mathrm{RC}$ frame to validate proposed flexural and axial damage criteria. They concluded from the obtained results that the proposed damage assessment criteria are valid and reliable for the progressive collapse analysis of RC frames. Dinu et al. [4] investigated the performances of four types of beam-to-column steel connections against progressive collapse by constructing Two-span frames and testing it under a central column removal scenario until failure. The tested specimens showed good ductility, with the catenary action making a significant contribution to the ultimate load resistance. The beams' ultimate rotations were higher than the deformation limit in Unified Facilities Criteria guidelines. Li [5] conducted a push-down analysis experimentally using a 1/3 scale one-story bare steel moment frame substructure. The test results reveal that flexural action plays an essential role in resisting progressive collapse along the entire loading process.

However, the catenary action becomes the primary collapse resisting mechanism in the final stage of loading. Dynamic responses of the test specimen are estimated using the energy-based method. The analysis results suggest that catenary action has a significant impact on the value of the dynamic increase factor under large deformation conditions. The three-dimensional reinforced concrete structure subjected to consecutive column loss scenarios with nonlinear dynamic response. According to Arshian et al. [6], a numerical approach is used to investigate sections subjected to consecutive column loss. It is found that theses sections suffered from more deformation compared to sudden single column failure scenarios.

An Experimental approach was used by Behnam et al. [7] and concluded that the effect of beam width to column width ratio on the seismic behavior of exterior reinforced concrete frame beam-column connection. Four specimens designed under (ACI318-14) and (ACI 352R-02) and tested under reversed cyclic loading conditions; Thus, he concluded that a wide beam could improve the joint shear capacity by enlarging the joint-effective width. Lu et al. [8] studied the interaction between beams and slabs and the two-way load transfer characteristics. Experimental testing was conducted on five 1/3-scaled RC frame substructure specimens, including four beam-slab specimens and one beam specimen without a slab, the slab contribution affected the progressive collapse resistance. The effect of critical structural parameters (i.e., the beam height, slab thickness, and seismic reinforcement) on the collapse resistance was investigated by analyzing the applied loads. A numerical investigation by Pham et al. [9] is conducted using the finite element method to check on the static and dynamic response under progressive collapse. Many verification procedures were performed to check the integrity of the model; in the actual verification, all parameters were investigated and resulted that under blast conditions, catenary action could be changed to prevent the structure collapse even if the bottom longitudinal reinforcement in the beam has already fractured. However, according to the authors, this method may have overestimated the structural resistance if a contact detonation event induces the localized damage. Some researches applied the column loss scenario induced by fire as Li et al. [10] presented it in an experimental study. They applied fire tests on five RC connections with varying reinforcement development lengths, with and without cooling effects using built hybrid heating furnace. They concluded that it is essential to provide practical recommendations for enhancing the structural robustness of structural configurations of the form considered in this study. Some studies scope on the precast connection's behavior due to progressive collapse, Al-Salloum et al. [11], studied how to strengthen the precast connections using bolted steel plates and Qian et al. [12], studied the resistance of high-performance dry connections due to progressive collapse. Tang et al. [13], studied and designed an asymmetric double-half-span single-column structure with a fully bolted connection in (RCS) frame structure. A static loading test is applied to a penultimate column 
to simulate the Colum loss scenario. Experimental and numerical assessment are carried out in the study, and a comparison between the two methods are concluded. It is found that the ultimate rotation angle of the connection obtained experimentally and numerically was higher than the allowable limit in the DoD (Department of Defense) guidelines. And finally concluded that enhancing the steel strength helped to improve the connection resistance towards progressive collapse. Also, Elsanadedy et al. [14], studied and analyzed reinforced concrete (RC) special momentresisting frame (SMRF) assemblies under column-loss scenarios considering bond-slip effects at the concrete-to-steel rebar interface using non-linear finite element method. They considered different parameters such as; type of assembly, column continuity, and development of beam rebars at exterior joints, applied axial loads on columns and beam continuity at exterior joints and studied its effect on the selected connection due to column loss.

As a result, a research sequence is applied to study the special moment frame connection behavior under column loss scenario as shown in Figure 1.

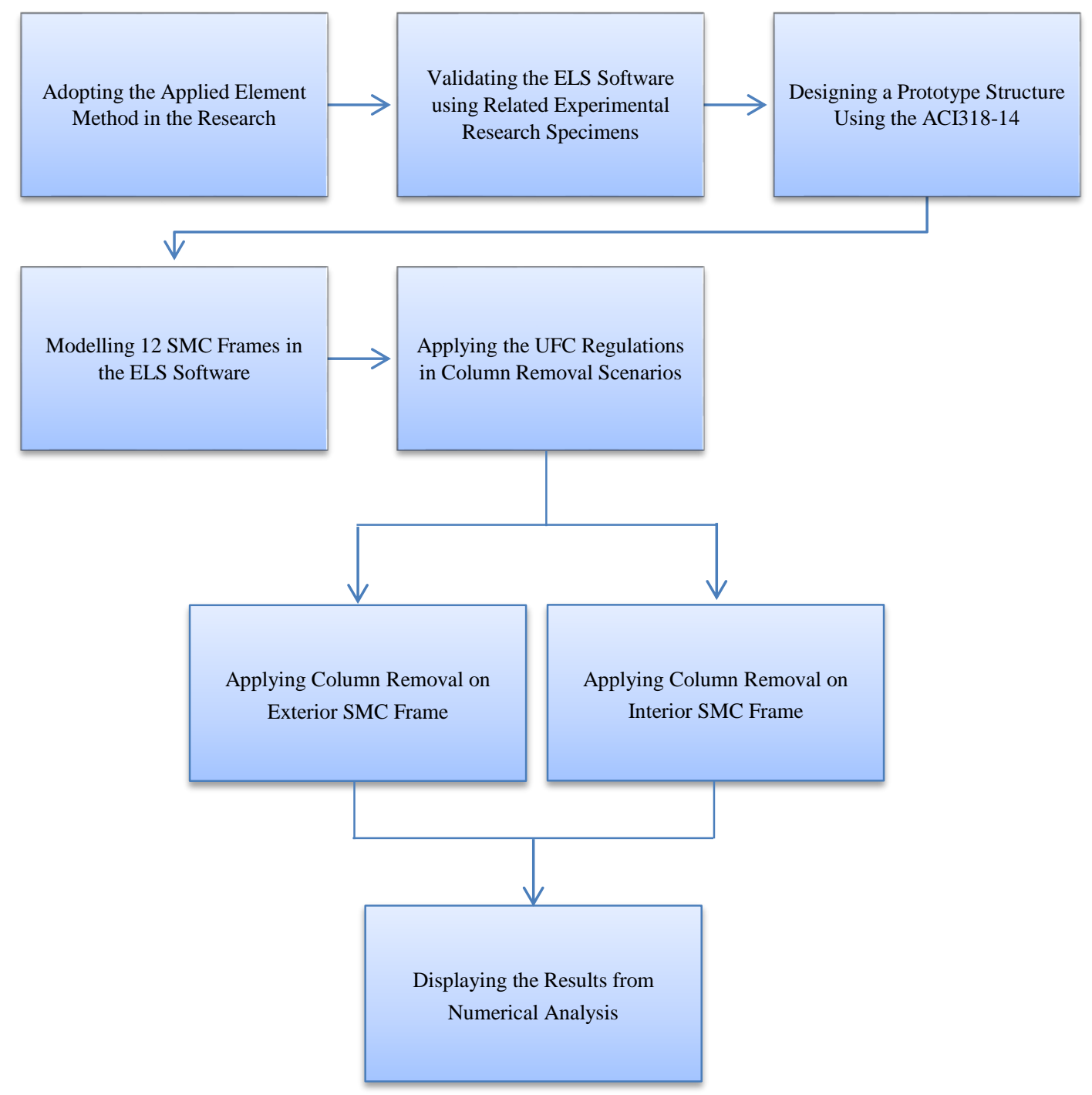

Figure 1. Description of the study workflow

\section{Research Methodology}

The Applied Element Method is an innovative modeling method adopting the concept of discrete cracking [15-17]. In Applied Element Method (AEM), the structures are modeled as an assembly of relatively small elements, made by dividing the structure virtually, as shown in Figure 2a. The elements are connected along their surfaces through a set of normal and shear springs. The springs are responsible for the transfer of normal and shear stresses, respectively, from one element to another. Springs represent stresses and deformations of a specific volume as shown in Figure $2 \mathrm{~b}$. 


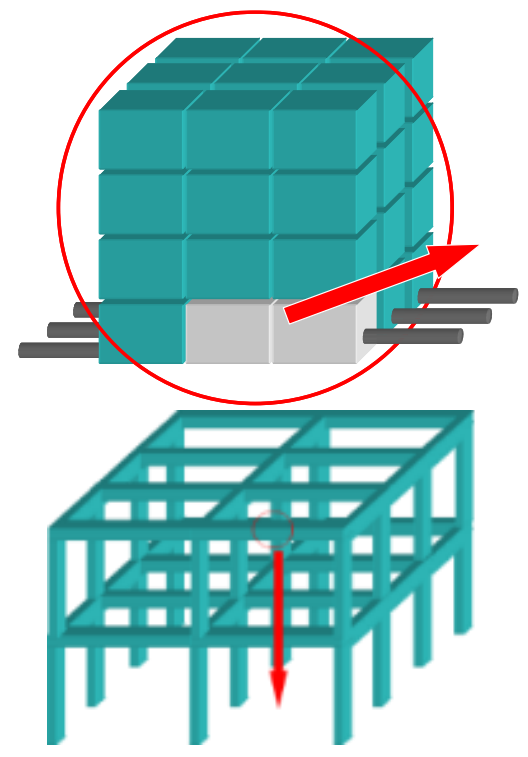

(a) Element Generation for AEM

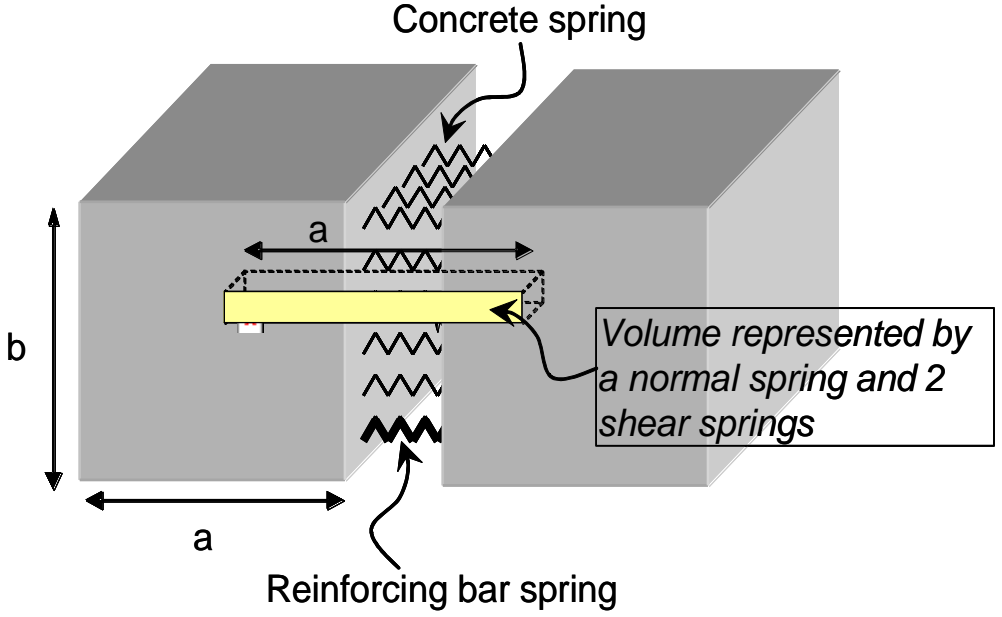

(b) Spring distribution and area of influence of each pair of springs

Figure 2. Modeling of structure to AEM [15]

Every single element has 6 degrees of freedom; 3 for translations and 3 for rotations. Relative translational or rotational motion between two neighboring elements causes stresses in the springs located at their common face as shown in Figure 3. These connecting springs represent stresses, strains, and connectivity between elements. Two neighboring elements can be separated once the springs connecting them are ruptured.
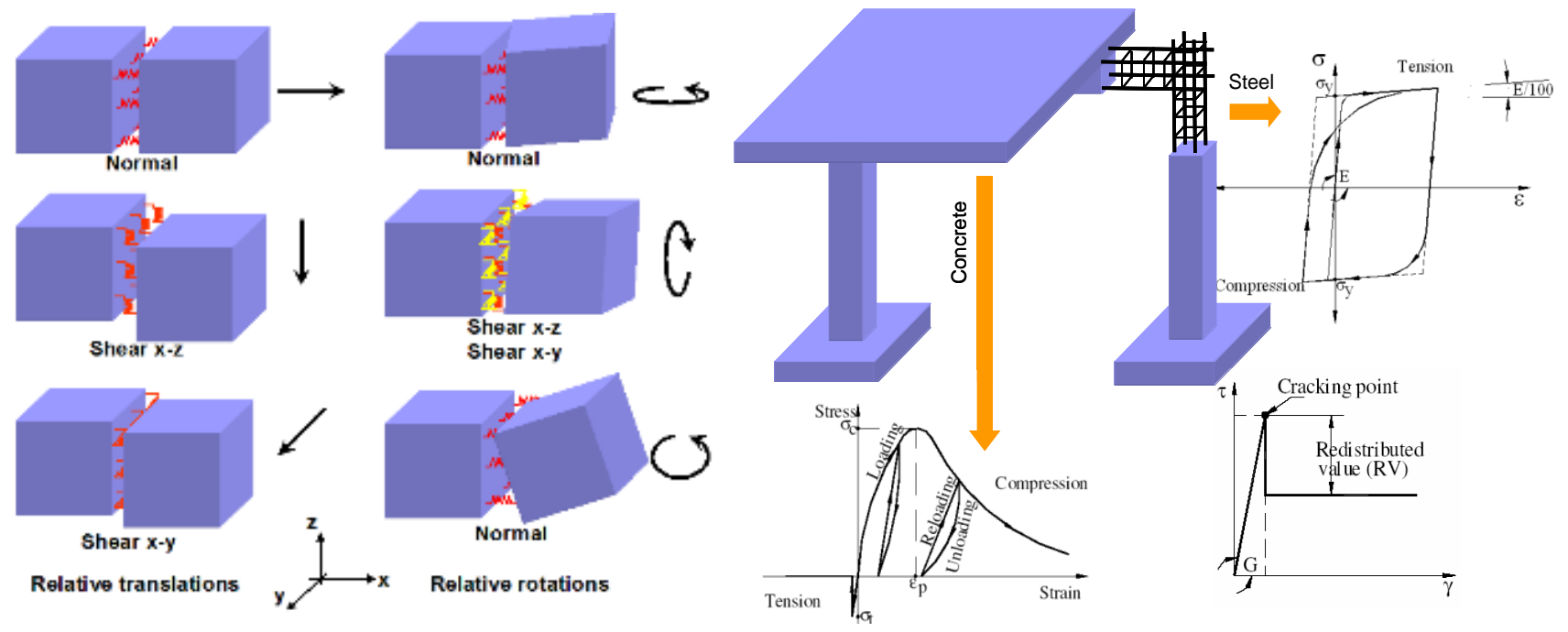

Figure 3. Stresses in springs due to relative displacements [15]

Figure 4. Constitutive models adopted in AEM for concrete and steel [15]

Fully nonlinear path-dependent constitutive models for reinforced concrete are adopted in the AEM as shown in Figure 4. For concrete in compression, an elasto-plastic and fracture model is adopted, Maekawa [19]. When concrete is subjected to tension, a linear stress-strain relationship is adopted until the cracking of the concrete springs, where the stresses then drop to zero. The residual stresses are then redistributed in the next loading step by applying the redistributed force values in the reverse direction. For concrete springs, the relationship between shear stress and shear strain is assumed to remain linear until the cracking of concrete. Then, the shear stresses drop down as shown in Figure 3. The level of the drop of shear stresses depends on the aggregate interlock and friction at the crack surface. For reinforcement springs, the tangent stiffness of reinforcement is calculated based on the strain from the reinforcement spring, loading status (either loading or unloading) and the previous history of steel spring which controls the Bauschinger's effect. The solution for the dynamic problem adopts implicit step-by-step integration (Newmark-beta) method Bathe and Chopra [20, 21]. Separated elements may collide with other elements. In that case, new springs are generated at the contact points of the collided elements. 


\section{Program Validation}

In this section, the ELS software is validated by analyzing the specimens tested by Weng et al. [3]. Three one-third scaled specimens are modeled and detailed using the ELS. A mesh sensitivity is conducted to choose the most suitable mesh in simulating the chosen specimen. The tested specimens are identified as Full Restrained (FR), full restrainseismic (FR-S) and Partially Restrained (PR). The detailing of the tested specimens, as well as the ELS models, are shown in Figures 5 and 6.

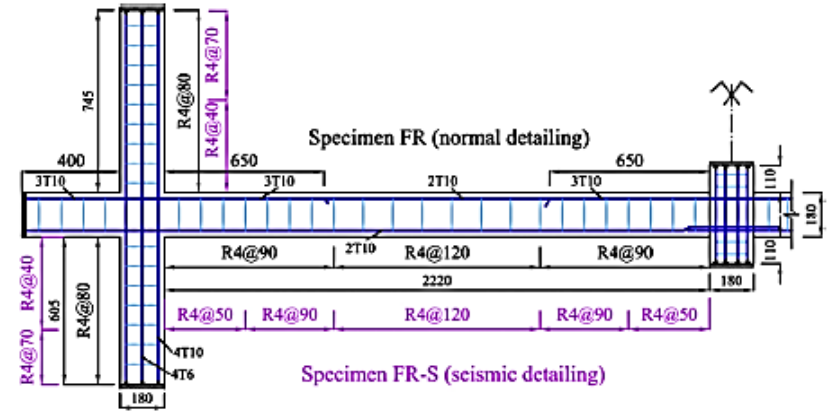

(a) Experimental Specimen Detailing (FR) and (FR-S)

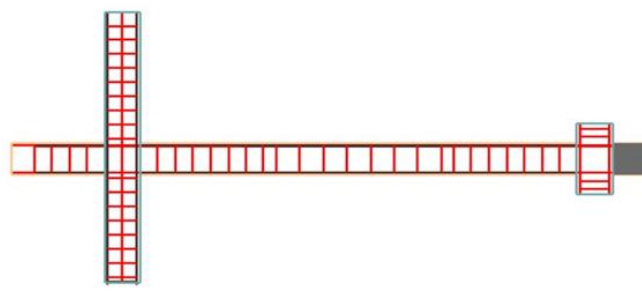

(b) ELS Model for (FR)

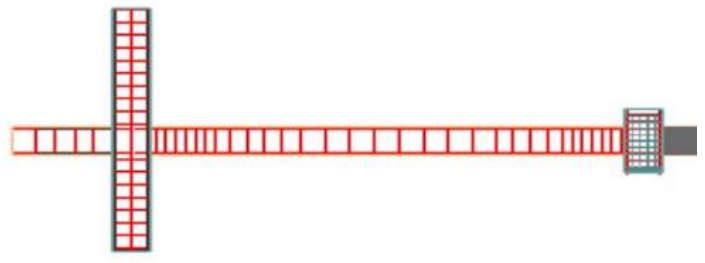

(c) ELS Model for (FR-S)

Figure 5. FR \& FR-S detailing [3] and modeling

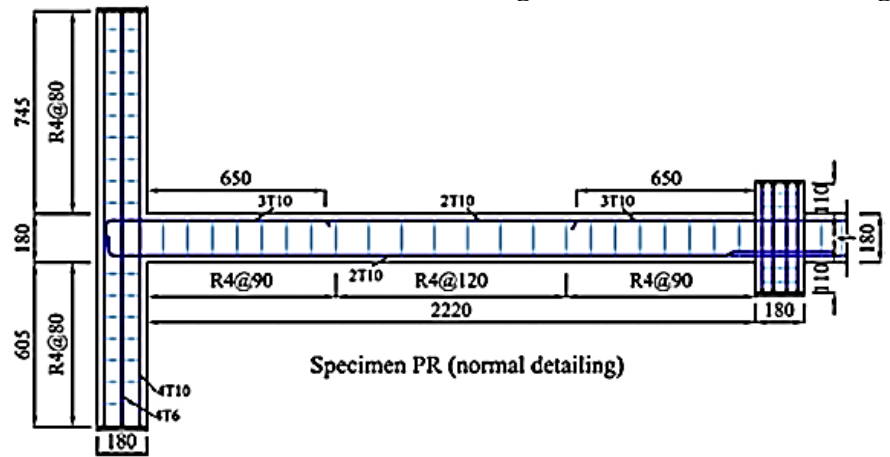

(a) Experimental Specimen Detailing (PR)

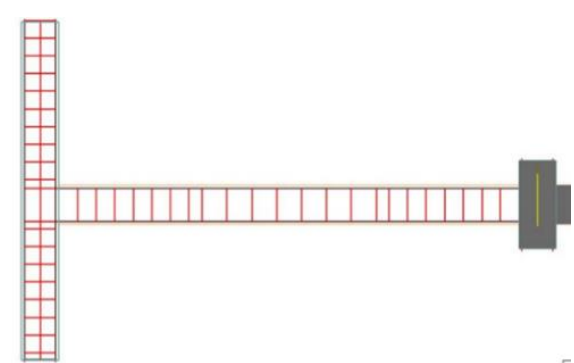

(b) ELS Model for (FR)

\subsection{Analysis of Results}

Figure 6. FR \& FR-S detailing [3] and modelling

Central deflection versus the applied load is shown in Figures 7 to 9. The analytical model shows acceptable results compared to the experimental results. The specimen encountered the same failure pattern as well as the same crack locations as shown in Figure 10.

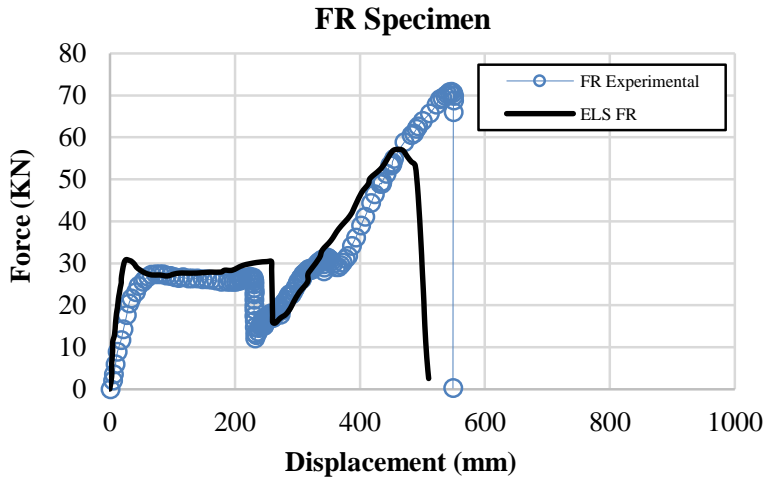

Figure 7. Load Versus Displacement for FR

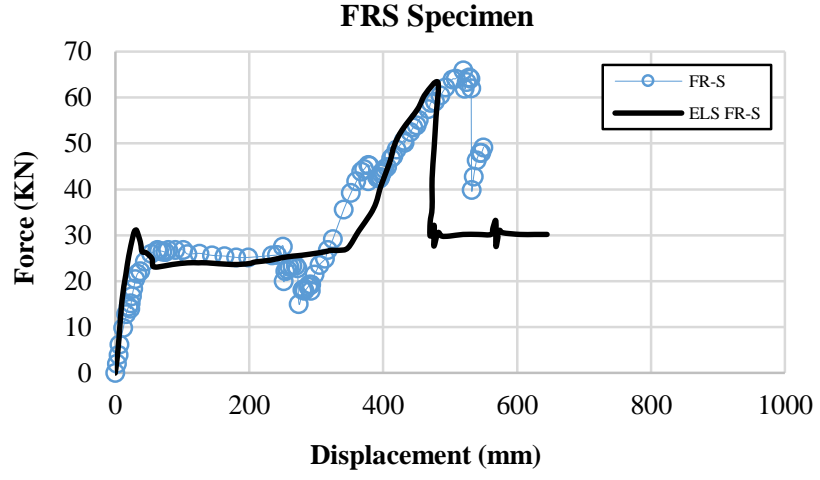

Figure 8. Load Versus Displacement for FR-S 


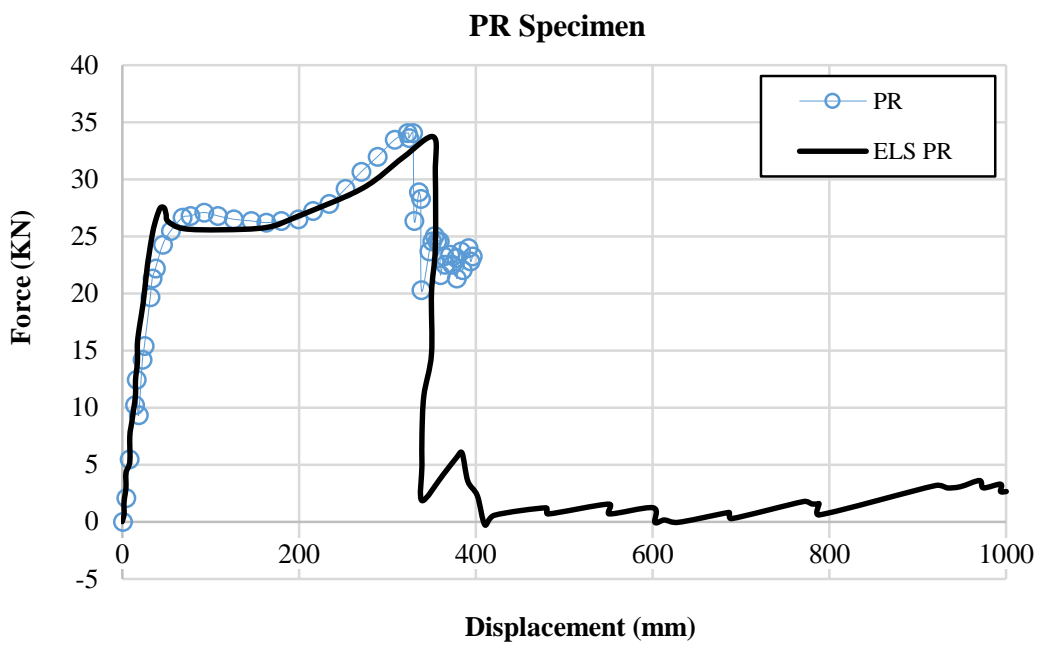

Figure 9. Load Versus Displacement for PR
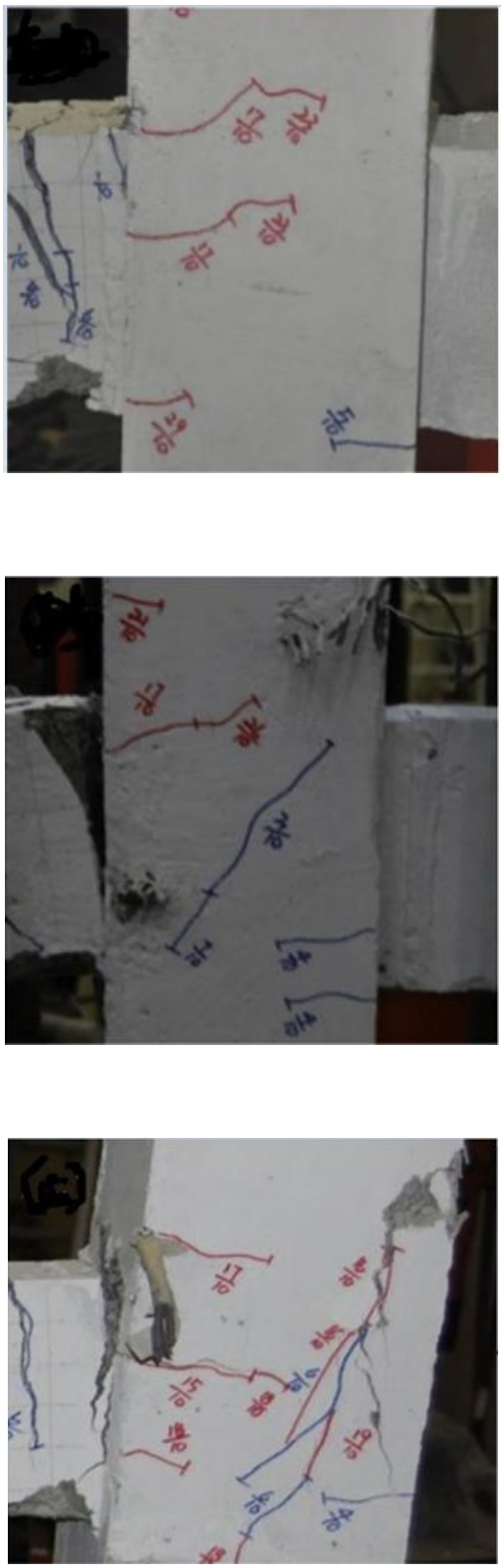

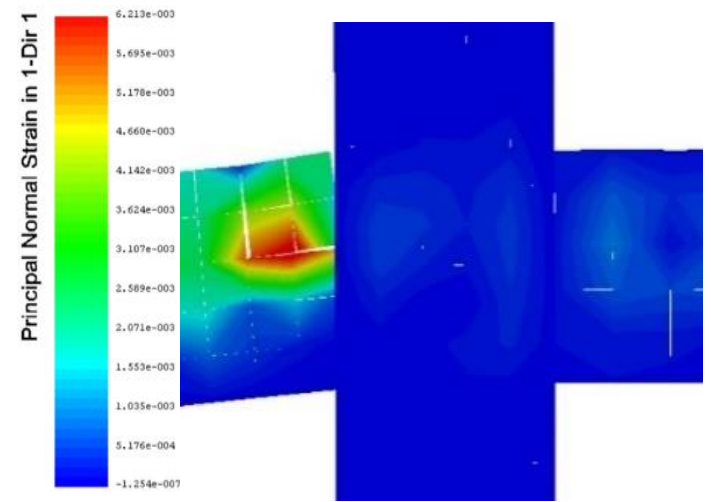

(a) FR Specimen

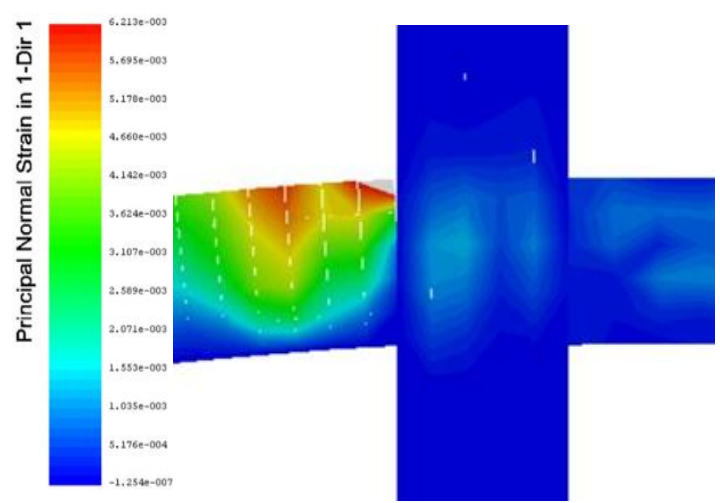

(a) FR-S Specimen

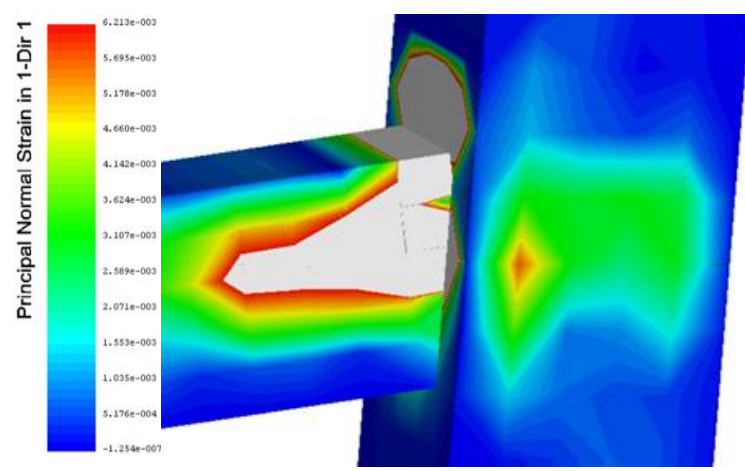

(c) PR Specimen

Figure 10. Failure in specimens 


\section{Numerical Case Study}

\subsection{Characteristics of Structure}

A prototype Special moment frame system is adopted in this study as shown in Figures 11 and 12. The structure is two-bay 10 meters length in both directions. The structure is designed to resist lateral loading by considering the weakbeam strong-column approach according to the ACI318-14 [22]. The structure is five stories with a clear floor height of $5 \mathrm{~m}$ with a Live load of $2 \mathrm{KN} / \mathrm{m}^{2}$. The material properties are taken as follows; $30 \mathrm{MPa}$ for concrete compressive strength and $360 \mathrm{MPa}$ yield strength for all steel bars. Girder and column dimensions with the selected reinforcement are illustrated as shown in Table 1. All slab and beam loads are calculated and applied to the frame girder itself.

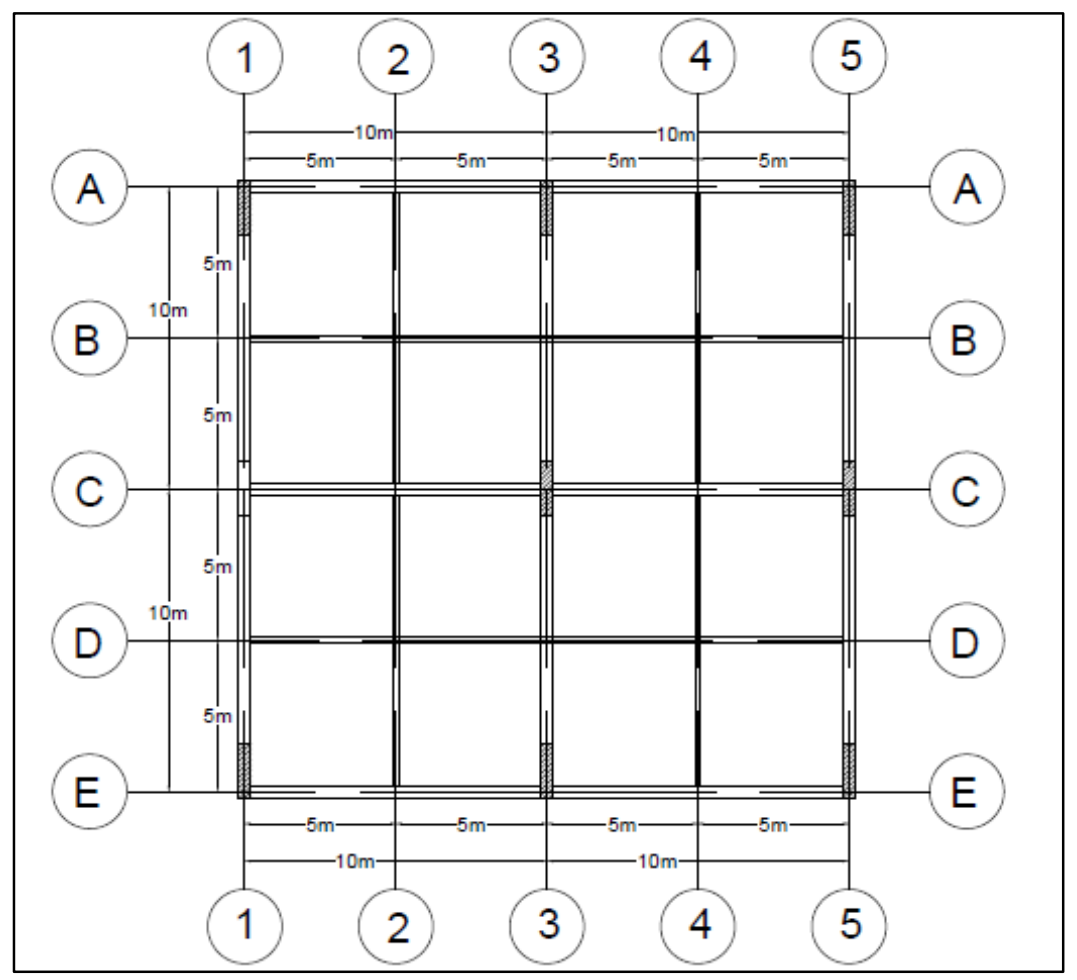

Figure 11. Structural Plan for the Prototype Structure
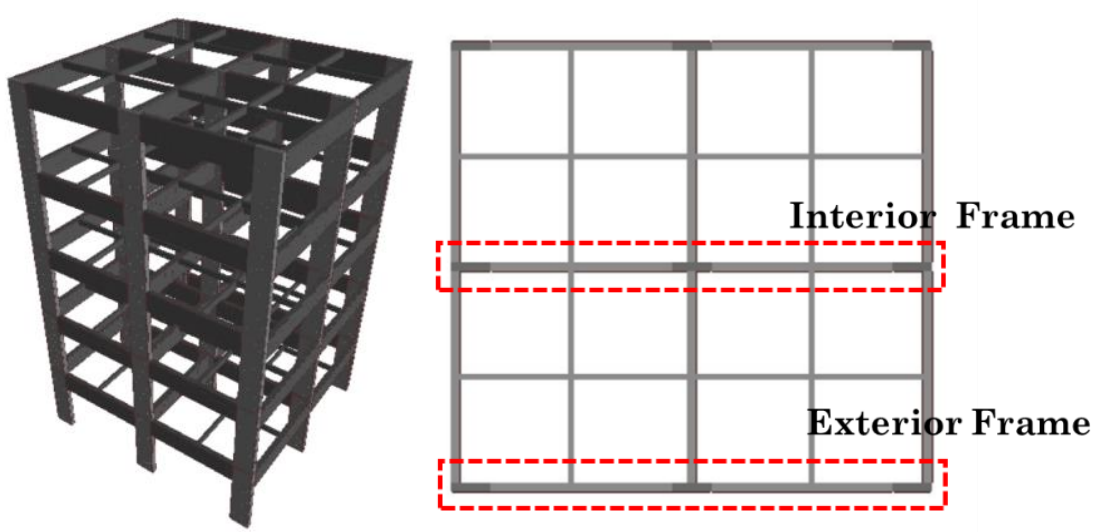

Figure 12. The adopted Case Study Structure

Table 1. Reinforcement detailing of the structural elements

\begin{tabular}{|c|c|c|c|}
\hline Exterior Frame & Cross section Dimensions (mm) & longitudinal Reinforcement & $\begin{array}{c}\text { Transverse } \\
\text { reinforcement }\end{array}$ \\
\hline Girder & $400 \times 1800$ & $4 \phi 22$ Top \& Bottom & $5 \phi 10 / \mathrm{m}^{\prime}$ \\
\hline Interior Frame & Cross section Dimensions (mm) & longitudinal Reinforcement & $\begin{array}{c}\text { Transverse } \\
\text { reinforcement }\end{array}$ \\
\hline Column & $400 \times 1800$ & $12 \varphi 25$ Uniformly Distributed & $5 \phi 12 / \mathrm{m}^{\prime}$ \\
\hline
\end{tabular}




\subsection{Numerical Modelling}

The structure is modeled in the ELS, two frames; exterior and interior frames, are chosen from the structure and studied separately with different column loss scenarios as shown in Figures 13 and 14. The column loss is applied on different floor levels by applying a load combination as the UFC 4-023-03 regulated [23]. The structure analysis is implemented using two stages of loading, the first stage where all the gravity loads are calculated and applied and the second stage where the column loss simulation took place. The column loss is simulated by removing all the column elements with respect to time starting from stage two in the analysis procedure. All boundary conditions for the columns are set to be fixed to the foundation.

The column loss scenario is applied in a certain pattern. For the exterior and interior frame, the column scenario is involved in two different locations one at a time, middle column loss and edge column loss as shown in different floor levels as shown in Figure 15.

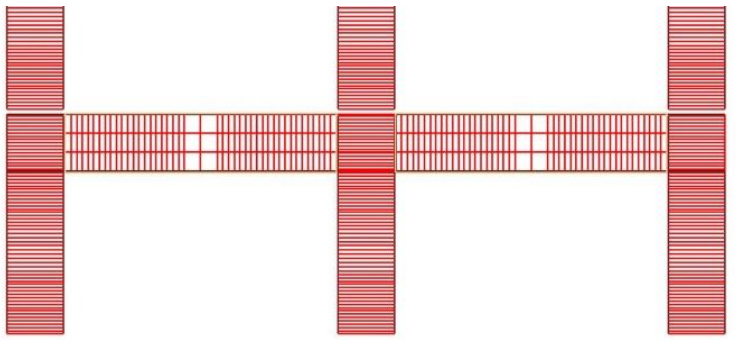

Figure 13. The Reinforcement Detailing in the ELS Model

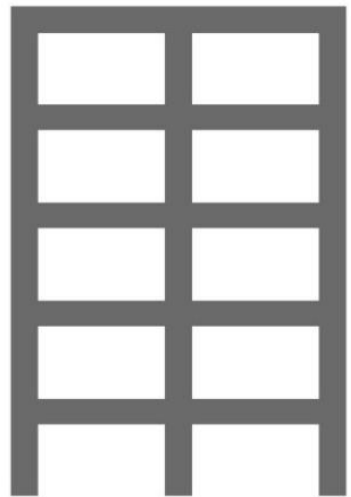

Figure 14. Exterior and Interior Frame in ELS

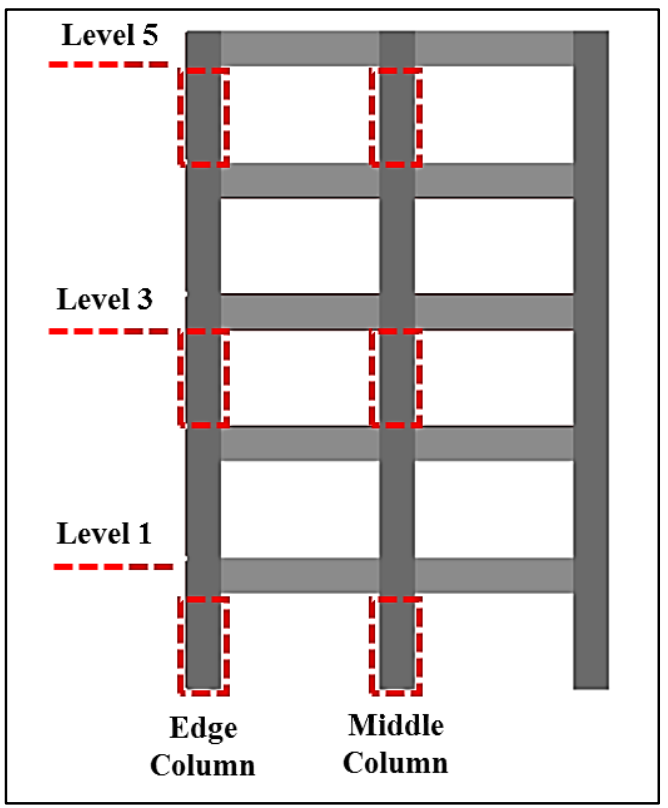

Figure 15. Column Loss scenario adopted

\section{Numerical Analysis and Results}

The results are presented for four main cases, middle column removal for exterior and interior frames for different floors and corner column removal for the same mentioned frames. Different behaviors are obtained for each case. The failure took place in the case of the Interior frame in most cases; however, no failure took place in the case of the Exterior frame.

The results obtained are in terms of beam deflection, shear applied in the Special moment connections, axial forces in beams, axial forces in columns, normal stresses in the top and bottom reinforcement in the concerned connection along with the redistribution of straining actions due to column loss. 


\subsection{The Results}

\subsubsection{Middle Column Removal}

\section{Failure pattern}

The Exterior frame did not fail on the contrary to the Interior frame. This expectancy comes from the fact that the Exterior frame carries half the loads compared to the Interior frame. Figure 16 shows the strain contours and the cause of failure for different cases.

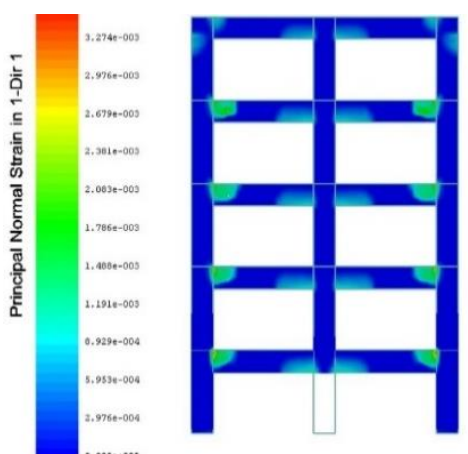

First floor

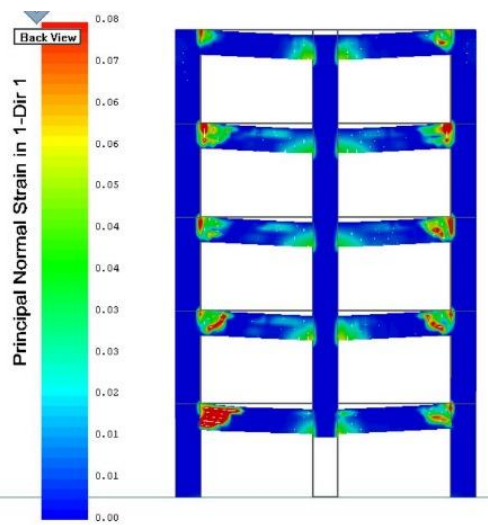

First floor

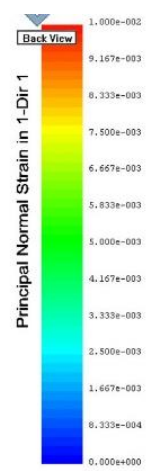

Third floor

(a) Exterior Frame

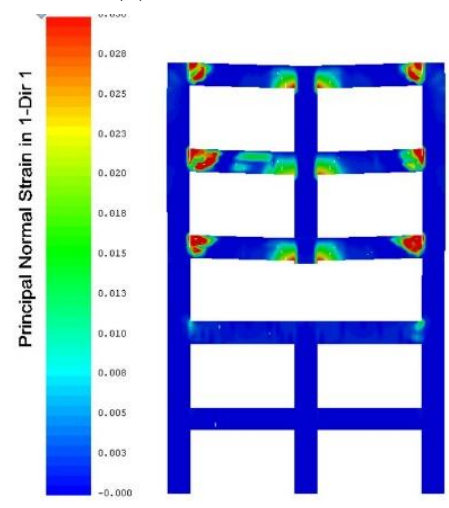

Third floor

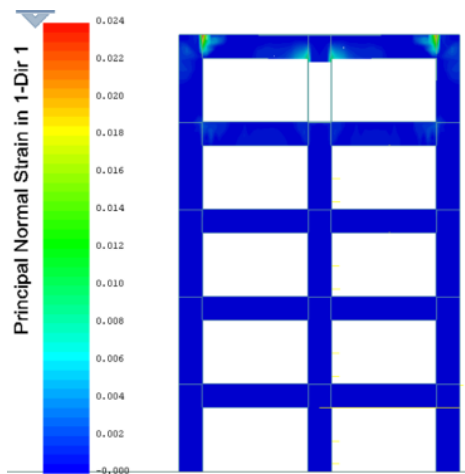

Fifth floor

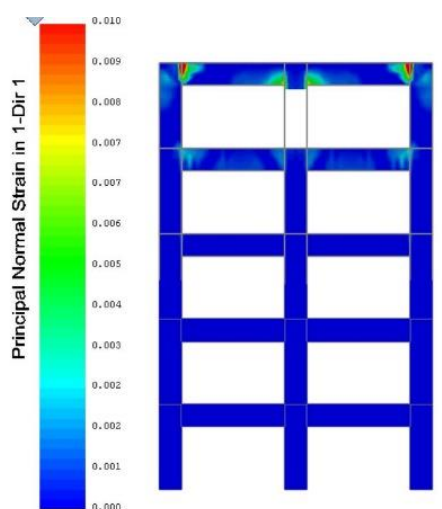

Fifth floor

(b) Interior Frame

\section{Beam Deflection}

Figure 16. Strain Contours for Different cases

The displacement is recorded at the location of the column removal. For the exterior frame, deflections vary from 22 $\mathrm{mm}$ for the first floor, $34 \mathrm{~mm}$ for the third floor and $28 \mathrm{~mm}$ for the fifth floor as shown in Figure 17. The first floor encountered the least deflection compared to the other floor levels. For the Interior frame, the first and the third floor failed to resist the column removal; however, the fifth floor stood still and stabilized after reaching 76 mm maximum displacement.

Exterior Frame (Middle Column Removal)

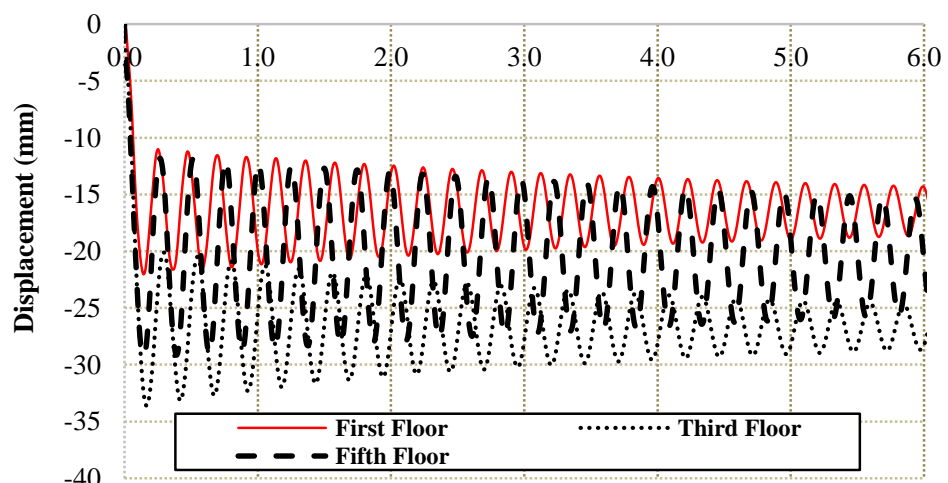

Time (Sec)

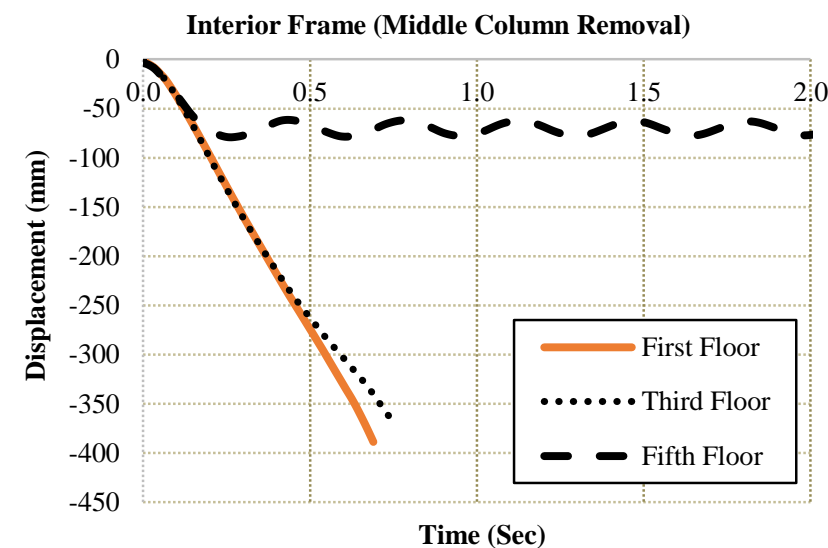

Time (Sec)

Figure 17. Deflection versus Time 


\section{Connection Shear force}

The connection shear force after column removal is obtained for both cases. No significant force is applied in the connection of the removed column. For the connections at the sides, the resistance of the structure towards column removal applied additional shear force on the connection as shown in Figure 18.

For the Exterior Frame, the maximum applied shear force in the connection reached 69 tons for the first-floor column removal, 68 tons for the third floor and 71 tons for the last floor column removal consequently. For the interior Frame, a maximum shear of 89.23 ton took place. For the Interior frames, shear forces are obtained at maximum values before the frame loses its stability. The maximum shear applied took place on the third floor with a value of 121.3 tons.

The maximum shear force took place in the column removal floors; this is because the compression arching effect of the beam along with the redistributed bending moment applied additional shear force on the designed connection. The joint capacity calculated previously for design purposes is 460 tons. So, the joint could withstand the applied shear force from column loss for both cases of interior and exterior frames.

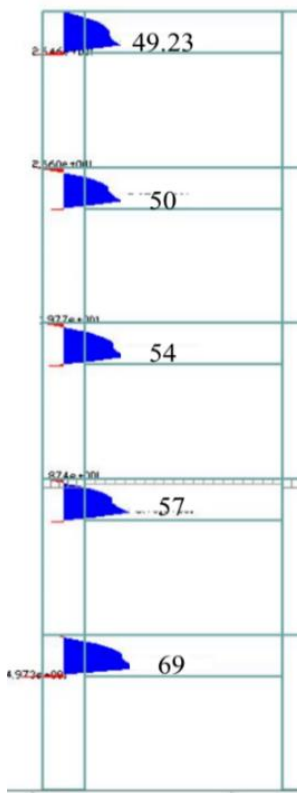

First Floor

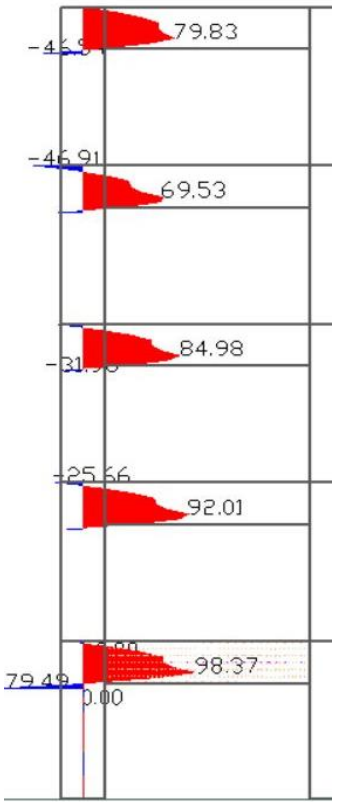

First Floor

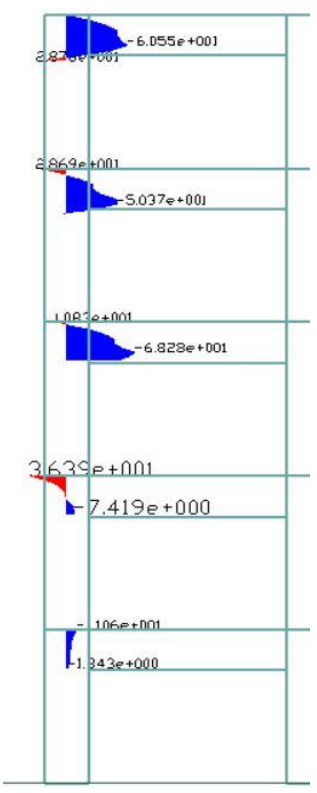

Third Floor

Exterior column

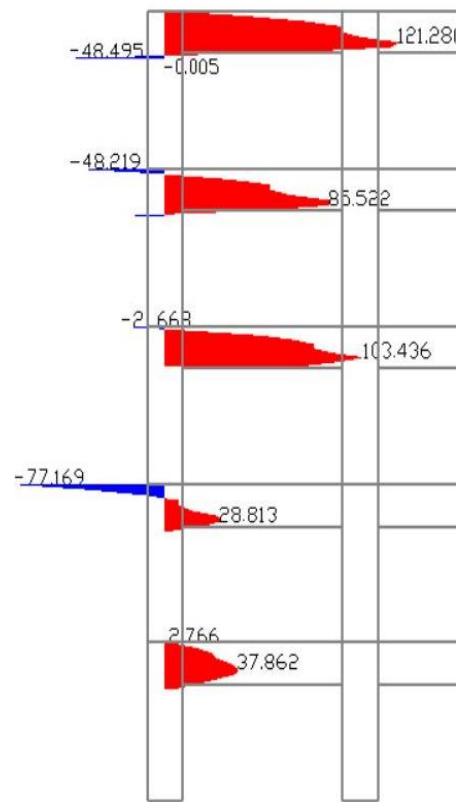

Third Floor

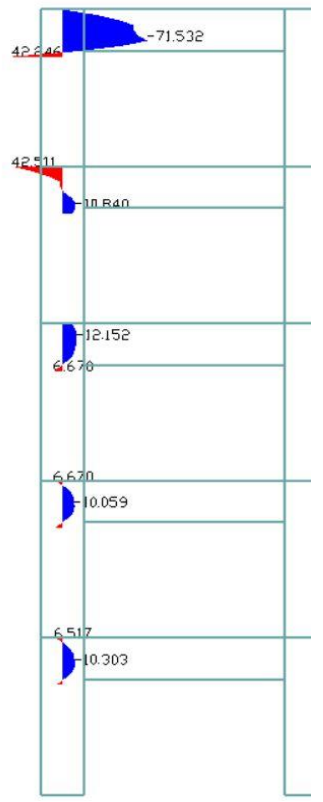

Fifth Floor

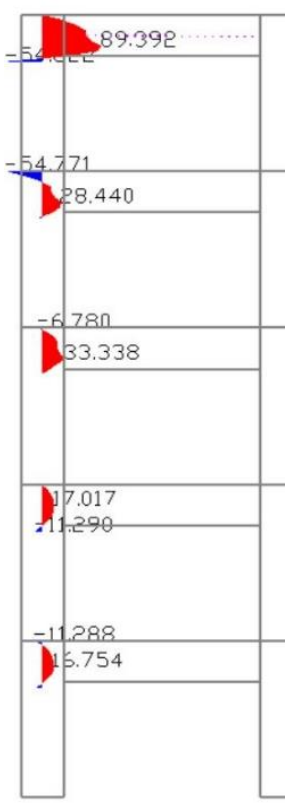

Fifth Floor

Interior column

Figure 18. Shear Force in Connection 


\section{Beam Axial Force}

The high compression force took place in the girders at the removed column location due to the compression arching effect. In the Exterior frame, the girder reached maximum compression of $450 \mathrm{KN}$ and then sustained the column loss for the first floor, $290 \mathrm{KN}$ for the third floor and $510 \mathrm{KN}$ for the fifth floor.

In the Interior frame, the girder subjected to high compressive stresses of $1500 \mathrm{KN}$ and then due to the high shear force applied, concrete crushing took place and affected the Concrete strength in compression as shown in Figure 19. For the third floor, maximum compression of $600 \mathrm{KN}$ took place before beam failure, and for the last floor level, the beam sustained the column loss and encountered a compression force of a maximum $630 \mathrm{KN}$ and remained stable.

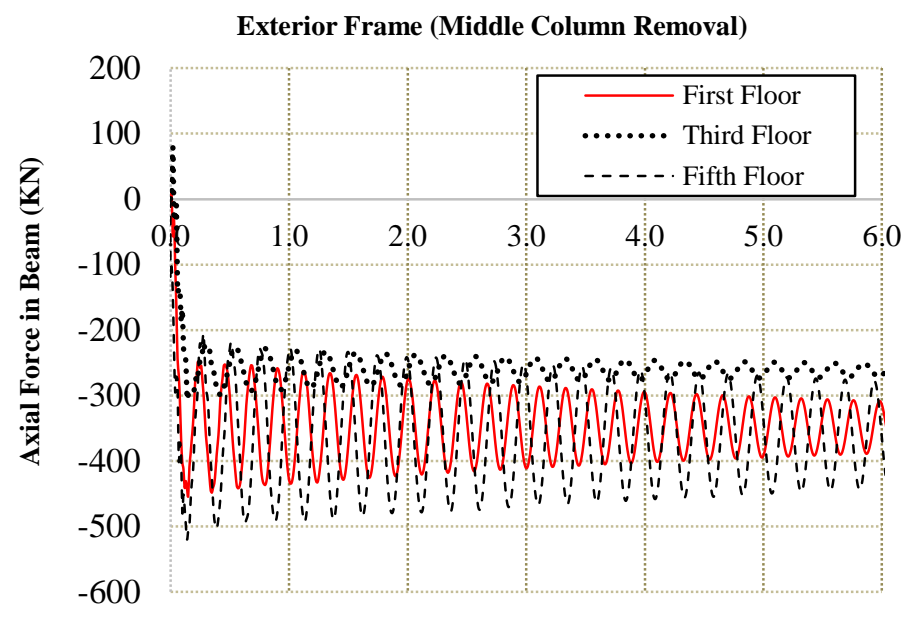

Time(Sec)

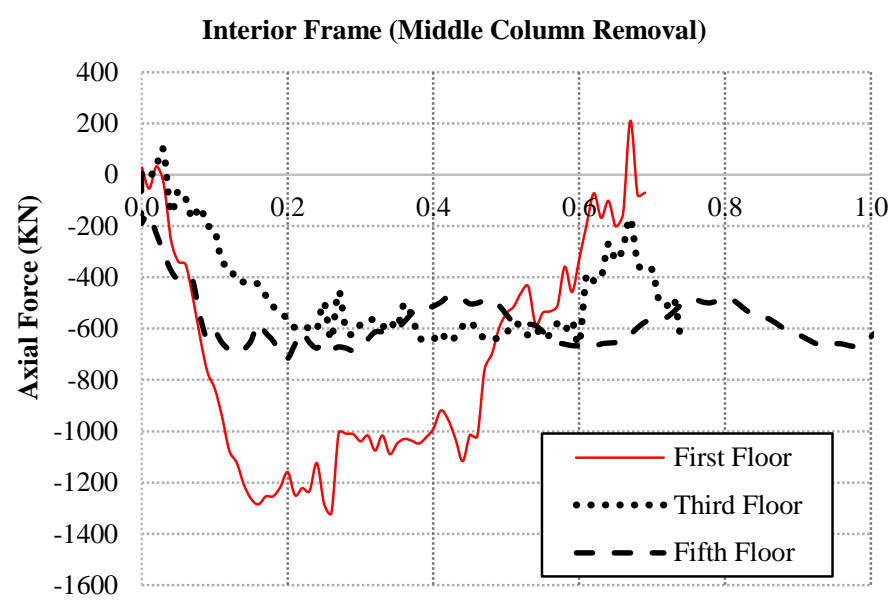

Time (Sec)

Figure 19. Axial force VS Time

Many parameters affect the frame behavior either to sustain column loss or to collapse. For the Exterior frame, the light loading along with the Vierendeel action helped in resisting and reducing the compressive force applied to the girders. The girders worked as a lateral restraint in cases of the first and third floors and sustained high tensile force shown in Figure 20. In the fifth-floor case, the girder subjected to a higher compression force due to the absence of the Vierendeel effect, as a result of increasing the load on the girder after column loss.

For the Interior frame, although failure took place in cases of first and third column removal, the Vierendeel action contributed to delay the failure for the first floor and increased the applied compression force resulting from the compression arching effect.

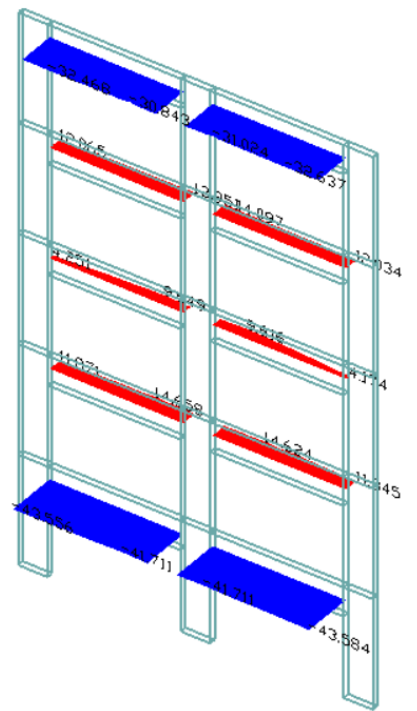

First Floor

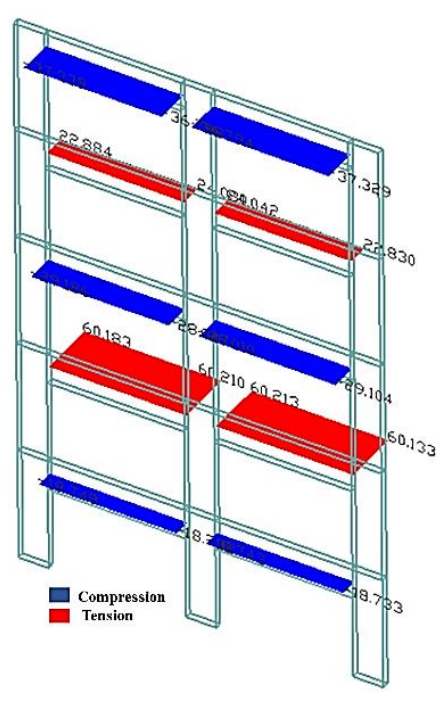

Third Floor

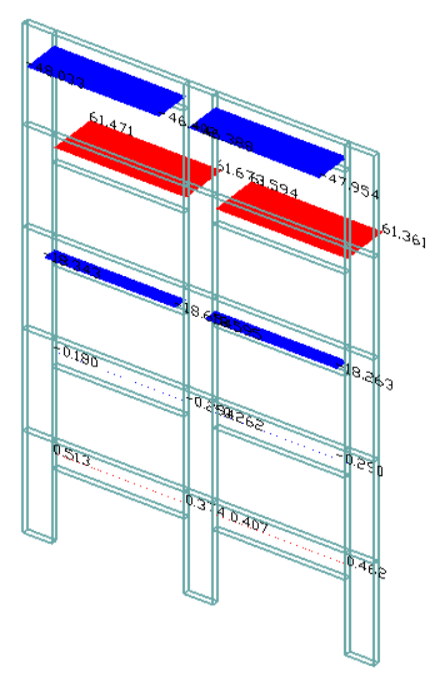

Fifth Floor

Exterior Frame 


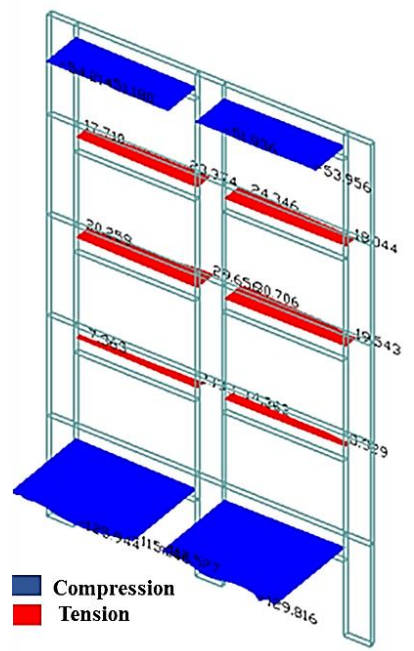

First Floor

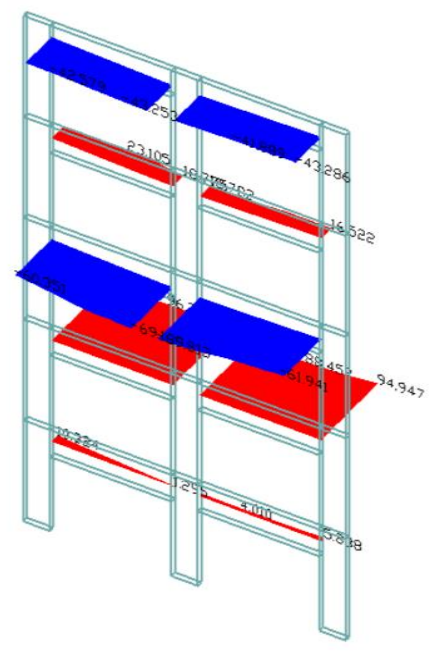

Third Floor

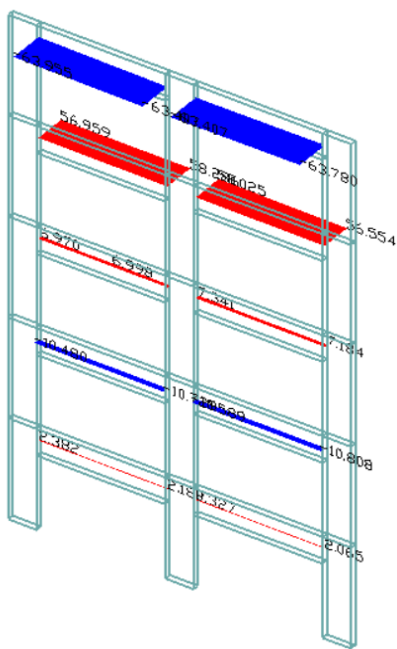

Fifth Floor

Interior Frame

Figure 20. Axial force Distribution in Frame girders

\section{Normal Stresses in reinforcement}

For the Exterior and interior frames, reinforcement locations studied are taken at the middle connections and the side connection. For each side, top and bottom reinforcement are rerecorded.

\section{- Top Reinforcement}

In the Exterior frame, for the three cases, the top reinforcement at the side connection reached its tensile yield stresses of $360 \mathrm{MPa}$ and then stabilized as shown in Figure 21. For the reinforcement at the column removal, the bars encountered compressive stresses due to the change in the structural system from being continuous to a simple beam. Each case faced different compressive stresses as shown in Figure 22. The maximum compressive stresses of 100, 140, and $80 \mathrm{MPa}$ for first, third and fifth-floor column removal took place.

In the Interior frame, at the side connection, for the first floor and the third floor, the reinforcement resisted high tensile stresses till ultimate, then shear failure took place before the rupturing of reinforcement at time 0.66 seconds. For the fifth floor, tensile stresses reached $400 \mathrm{MPa}$ and then stabilized.

At the column removal connection, the reinforcement for the first and third floors encountered maximum compressive stresses of 420 and $360 \mathrm{MPa}$ before the beam shear failure. For the fifth floor, the top reinforcement reached $200 \mathrm{MPa}$ maximum compressive stresses and then stabilized as shown in Figures 21 and 22 respectively.
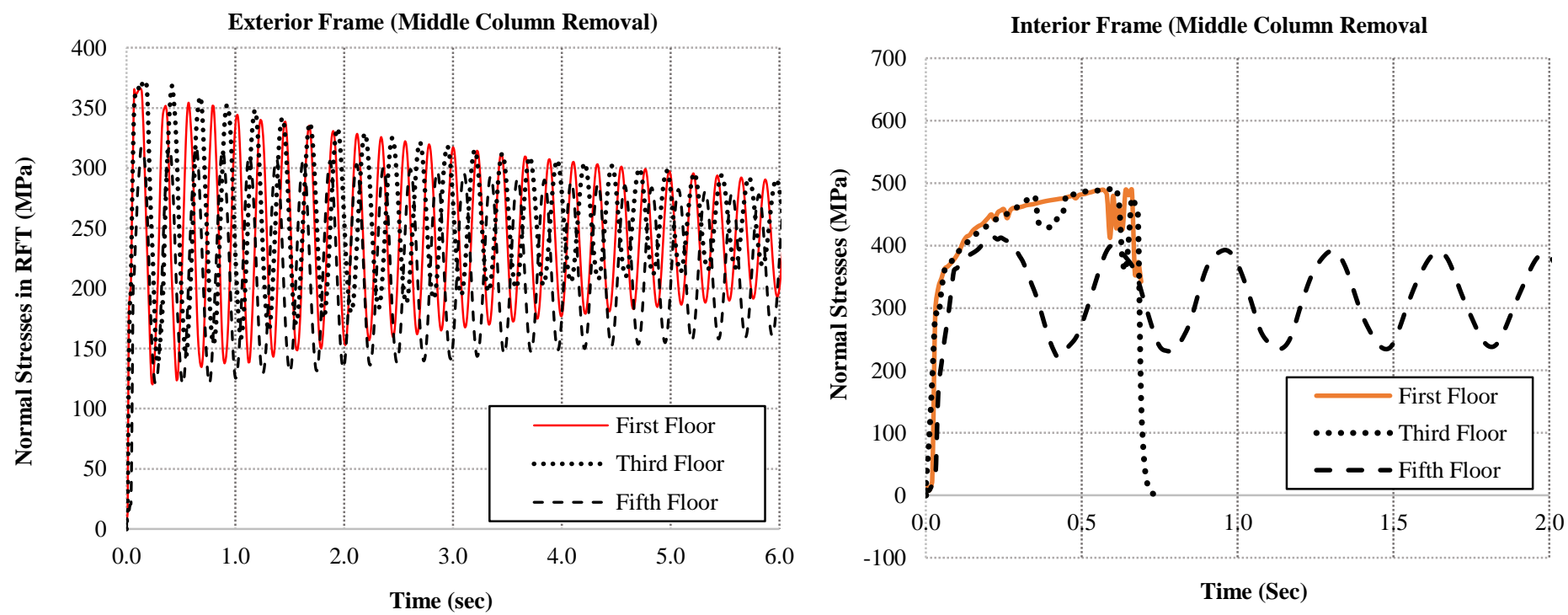

Figure 21. Normal Stresses in Top Side RFT versus Time at sides 

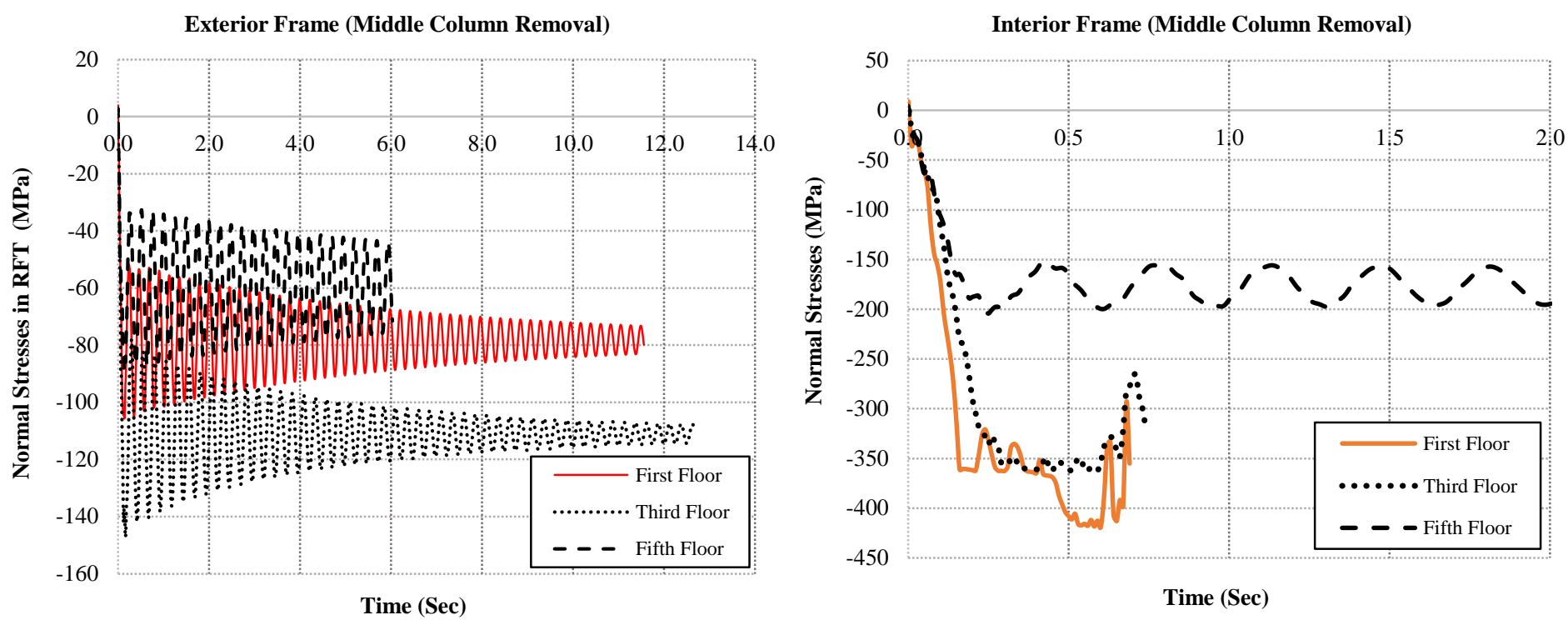

Figure 22. Normal Stresses in Top Side RFT versus Time at column removal

\section{- Bottom Reinforcement}

The normal stresses in bottom reinforcement for both Exterior and Interior frames are calculated as shown in Figures 23 and 24. For the bottom reinforcement at the sides, the reinforcement encountered compressive stresses due to the applied negative bending moment on the connection. For the Exterior frame, the maximum stresses of $200 \mathrm{MPa}$ took place for the third floor and then stabilized.

For the Interior frame, the bottom reinforcement failed for the first and third cases. The first floor failed earlier after reaching maximum stresses of $498 \mathrm{MPa}$. The fifth floor reached $360 \mathrm{MPa}$ and then stabilized.

At the column removal location, the bottom reinforcement of the Exterior frame reached maximum stresses of 360 $\mathrm{MPa}$ for the third-floor case. And for the Interior frame, the first and third-floor cases, the reinforcement rupture at the same time after reaching $450 \mathrm{MPa}$ tensile stresses.

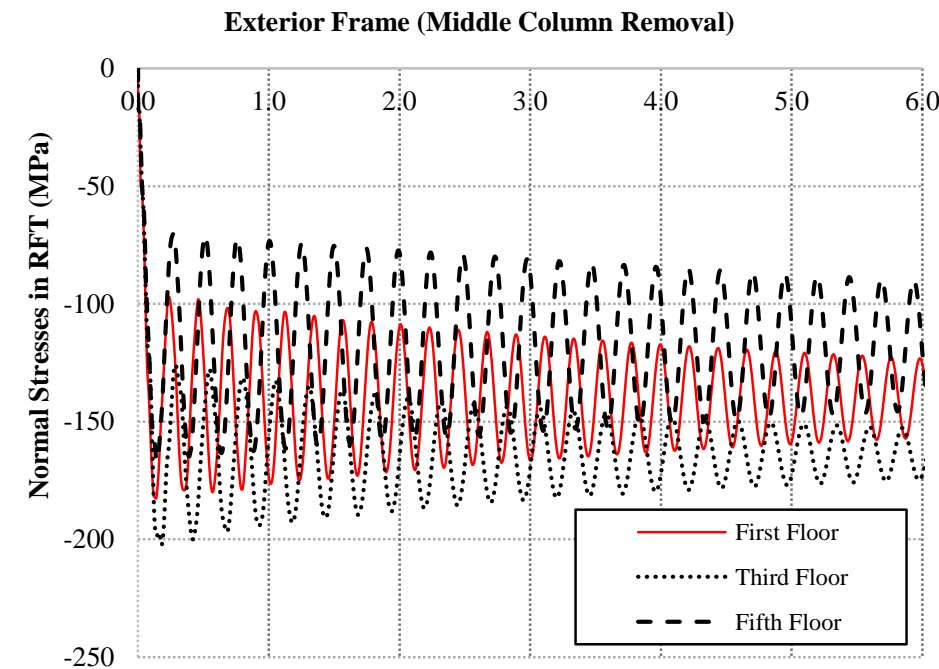

Time (Sec)

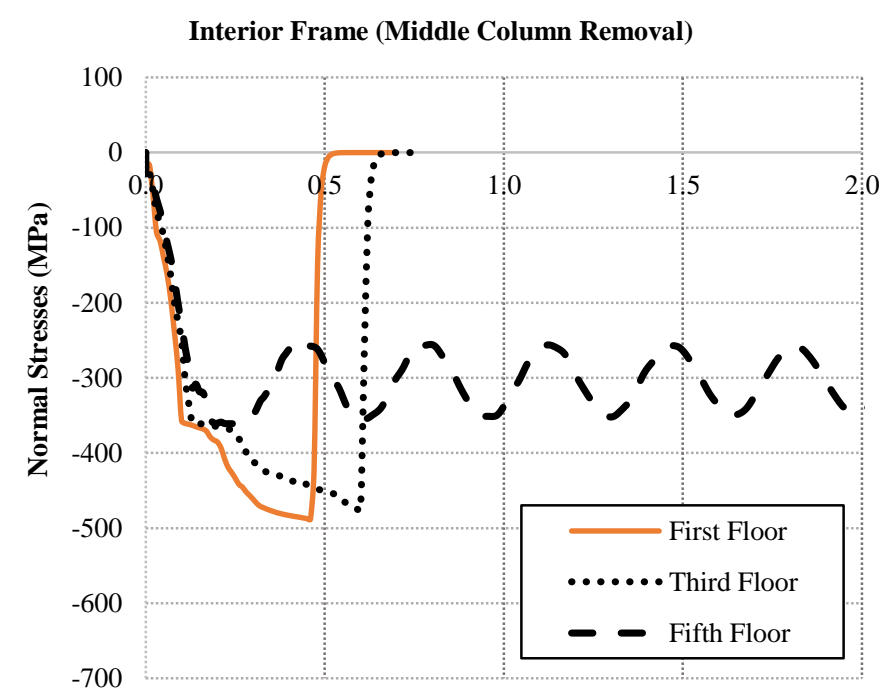

Time (Sec)

Figure 23. Normal Stresses in bottom RFT versus Time at sides 
Exterior Frame (Middle Column Removal)

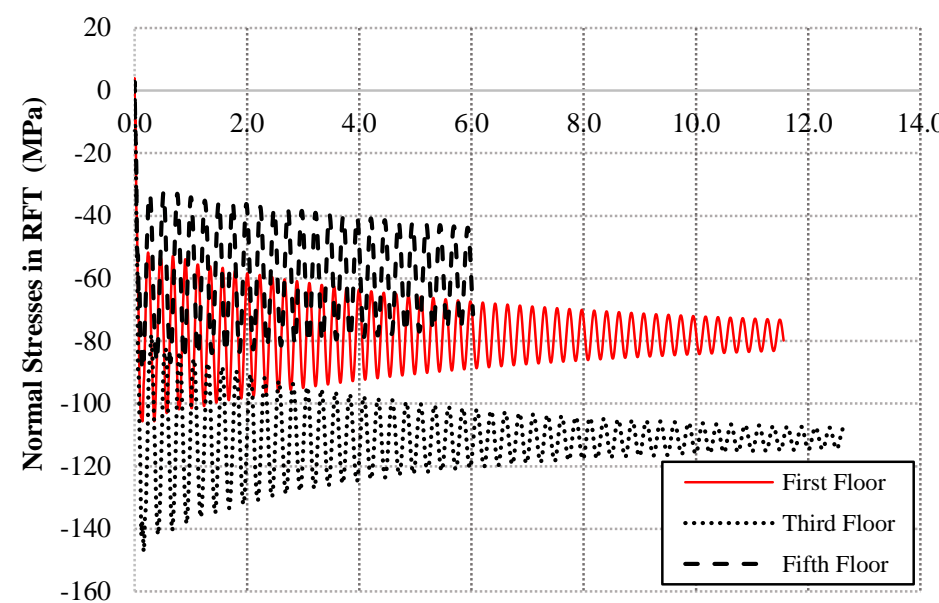

Time (Sec)
Interior Frame (Middle Column Removal)

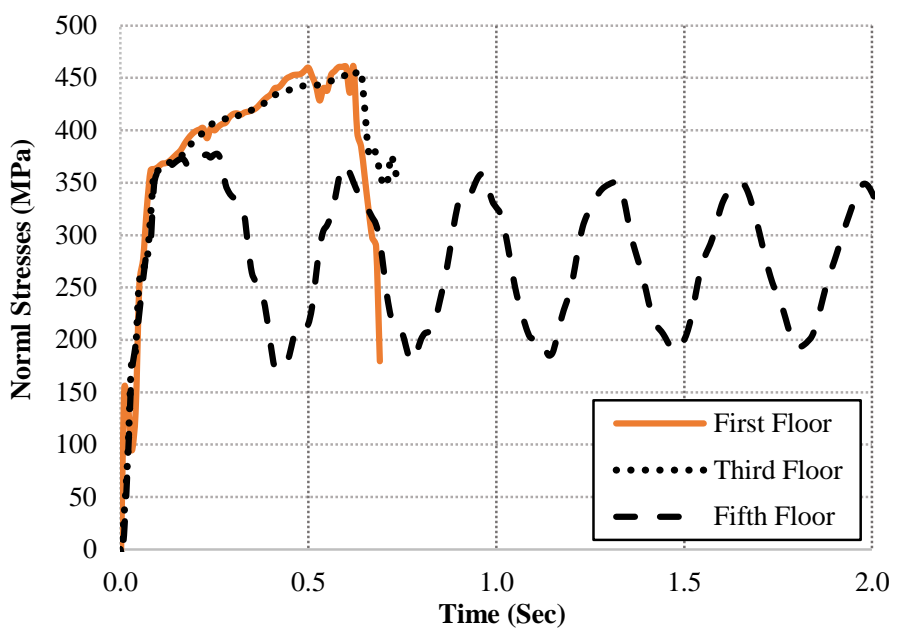

Figure 24. Normal Stresses in bottom RFT versus Time at column removal

\section{Column axial forces and Rotations}

For the Exterior frame, the increase in the axial forces in surrounding columns due to column removal is observed as follows; $82 \%$ increase in the first-floor case, $46 \%$ for the third-floor case and $23 \%$ for the fifth floor. For the Interior frame, no increase is calculated due to its collapse. Column rotations are calculated for the Exterior frame case, and all cases met the UFC rotation limits.

\subsubsection{Edge Column Removal}

The second part of the case study is the edge column removal from the exterior and the interior frames. The same parameters are studied.

\section{Failure Pattern}

For the exterior frame, the frame sustained the column removal for the three cases, on the contrary of the interior frame cases as shown in Figure 25

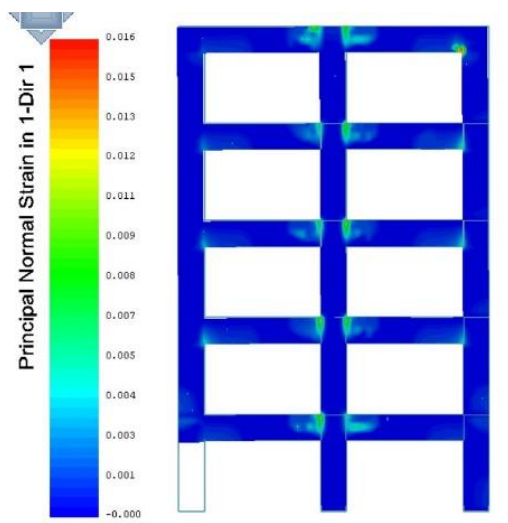

First Floor

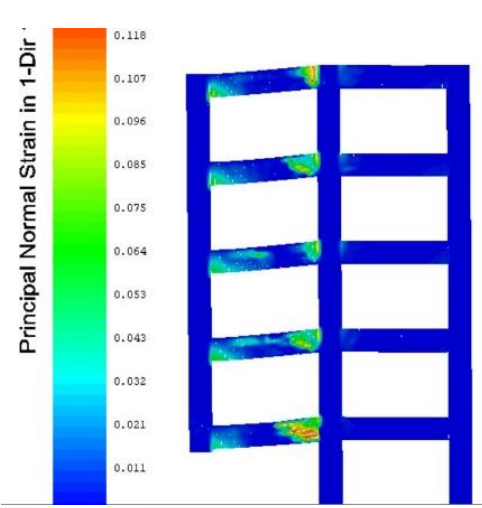

First Floor
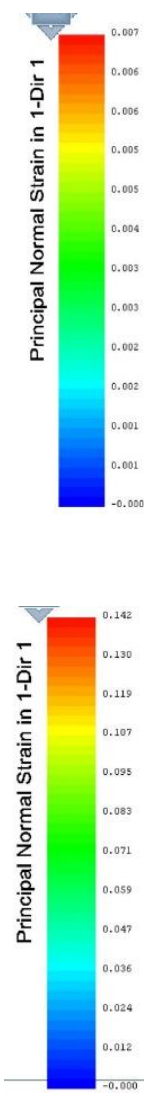
Exterior Frame

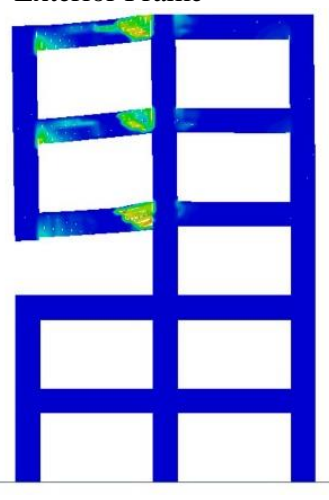

Third Floor

Interior Frame
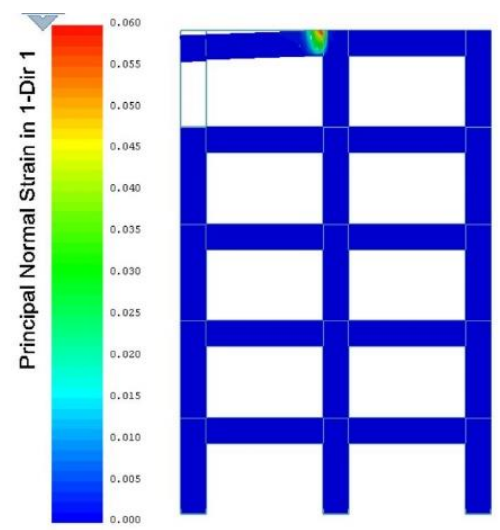

Fifth Floor

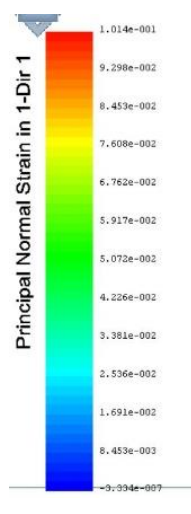

Fifth Floor

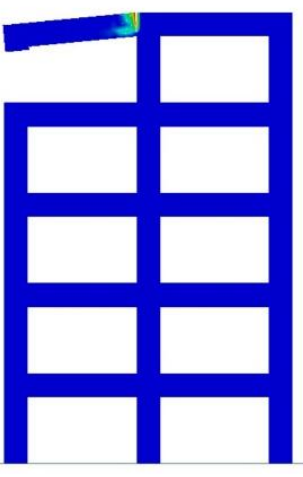

Figure 25. Strain Contours for different cases 


\section{Beam Deflection}

The displacement is recorded at the location of the column removal. For the exterior frame, deflections vary from 86 $\mathrm{mm}$ for the first floor, $71 \mathrm{~mm}$ for the third floor and $324 \mathrm{~mm}$ for the fifth floor as shown in Figure 26. For the Interior frame, the three cases failed to resist the column removal.

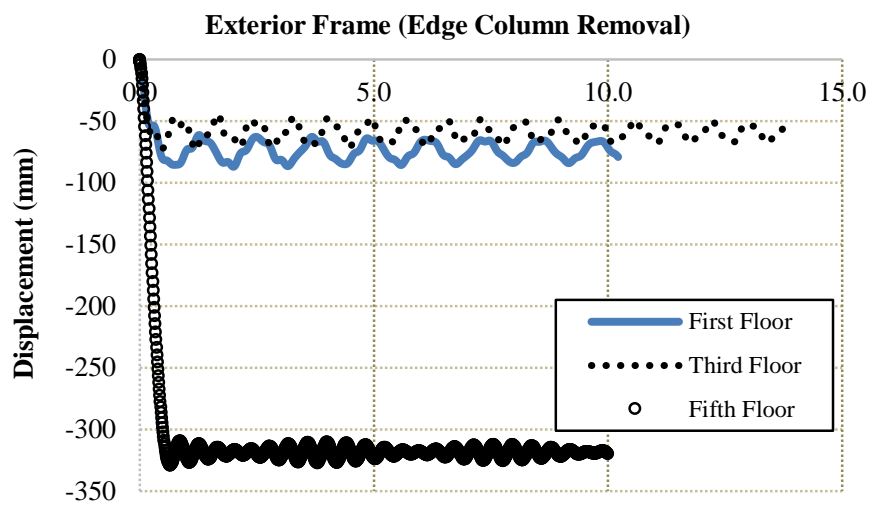

Time (Sec)

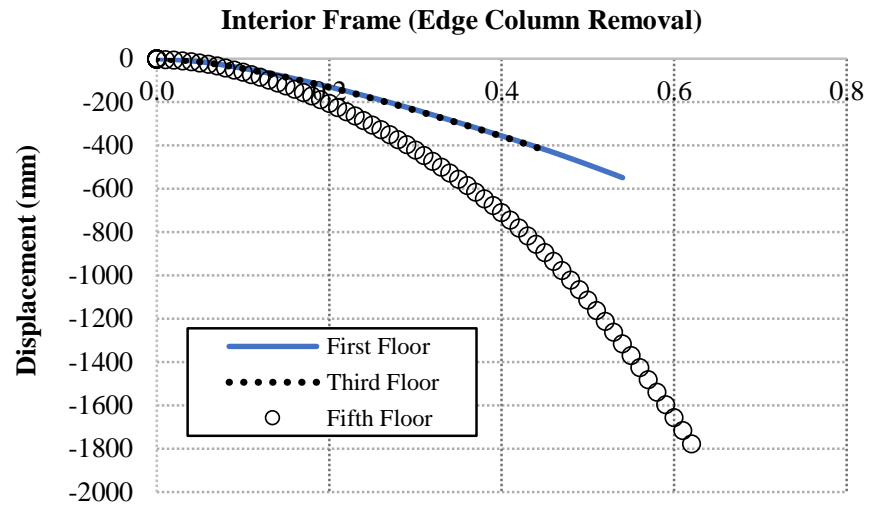

Time (Sec)

Figure 26. Deflection versus Time

\section{Connection Shear force}

The connection shear force after column removal is obtained for both cases. For the Exterior Frame, the maximum applied shear force in the connection reached 70 ton, 63 tons for the third floor and 71 ton for the last floor column removal at the removed column connection. For the interior Frame, a maximum shear of 89.23 ton took place. For the Interior frames, shear forces are obtained at maximum values before the frame loses its stability. The maximum shear applied took place on the third floor with a value of 121.3 tons.

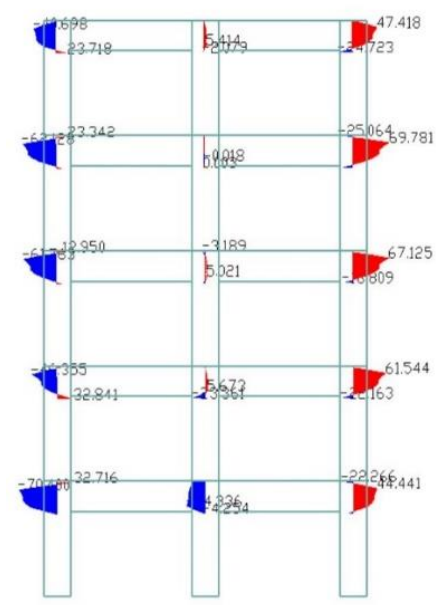

First Floor

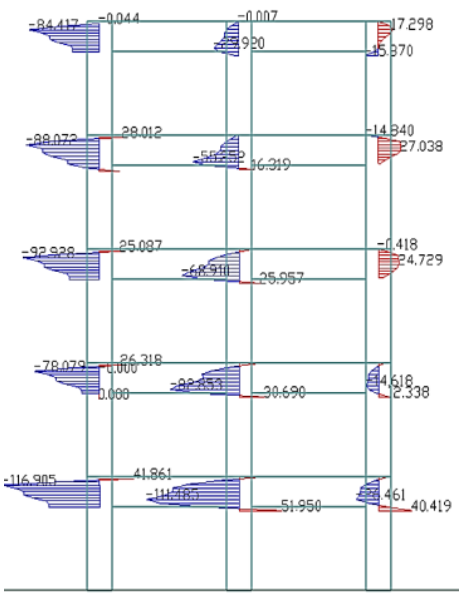

First Floor

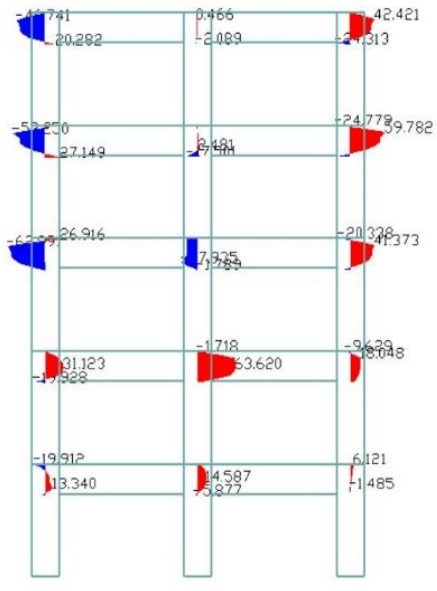

Third Floor

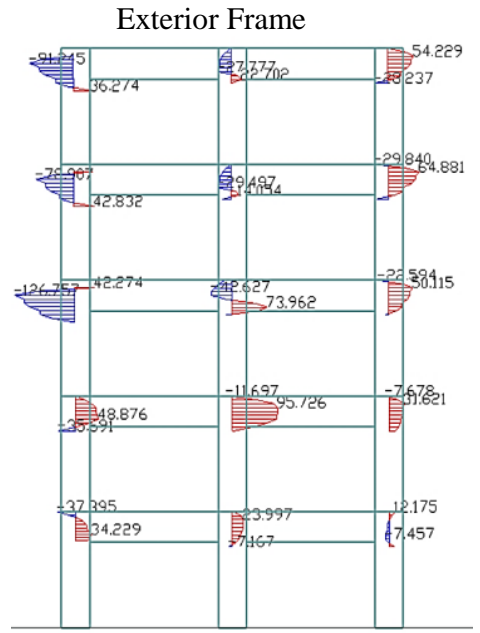

Third Floor

Interior Frame, just before failure

Figure 27. Shear Force in Connection

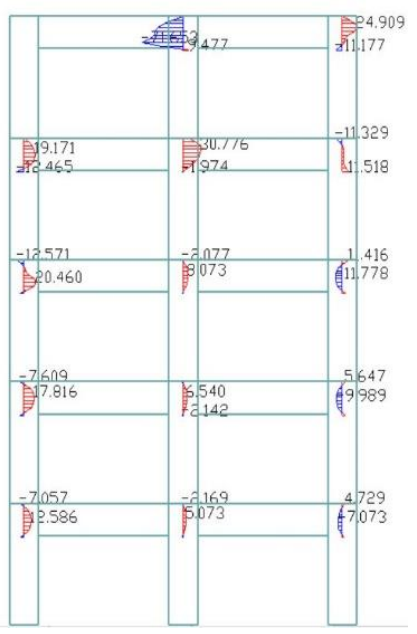

Fifth Floor

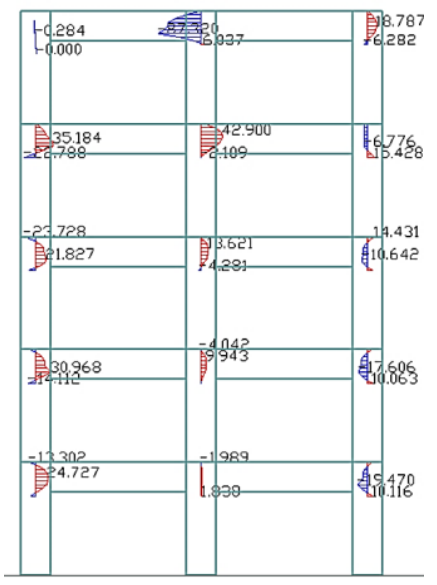

Fifth Floor 


\section{Beam Axial Force}

In the Exterior frame, the girder reached maximum compression of $400 \mathrm{KN}$ and then sustained the column loss for the first floor, $350 \mathrm{KN}$ for the third floor and zero force for the fifth floor.

In the Interior frame, the girder subjected to high compressive stresses of $500 \mathrm{KN}$ for both first and third-floor cases and then shear failure took place as shown in Figure 28. For the last floor, no compression arching phenomenon took place, and the beam failed due to high negative bending moments resulted from load redistribution due to column loss.

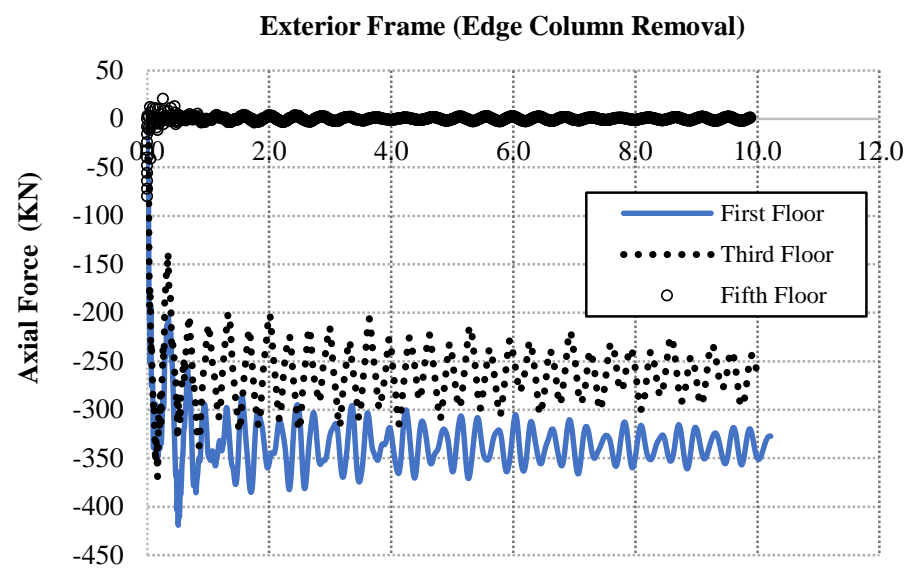

Time (Sec)

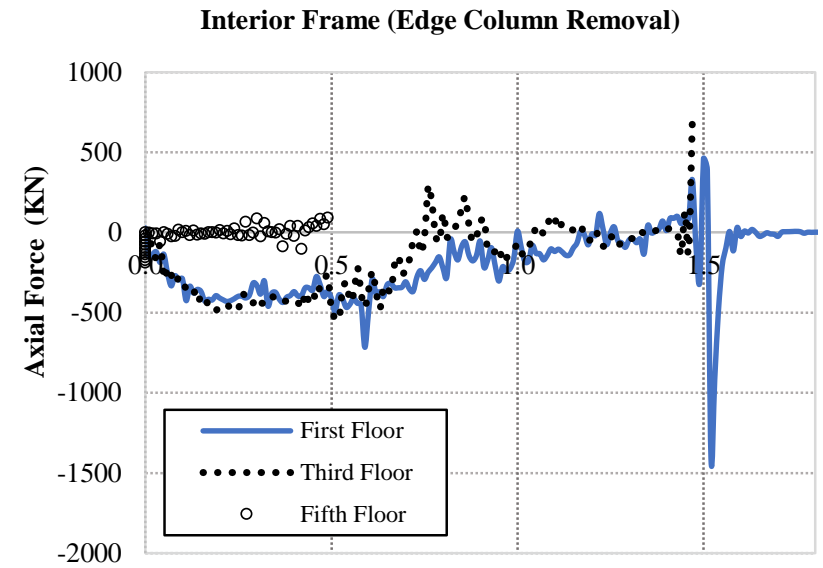

Time (Sec)

Figure 28. Axial force VS Time

\section{Normal Stresses in reinforcement}

The reinforcement locations studied are taken at the column removal and the side connection. For each side, top and bottom reinforcement are rerecorded.

\section{- Top Reinforcement}

In the Exterior frame, the fifth floor reached maximum stresses of $500 \mathrm{MPa}$ higher than the first and third-floor cases and then stabilized. For the reinforcement at the column removal, the bars encountered compressive stresses due to the change in the structural system. Each case encountered different compressive stresses as shown in Figure 29. The maximum compressive stresses of $100 \mathrm{MPa}, 120 \mathrm{MPa}$, and Zero for first, third and fifth-floor column removal took place.

In the Interior frame, at the side connection, for the three cases, the reinforcement resisted high tensile stresses till the rupture of reinforcement. The fifth-floor case reinforcement rupture took place earlier than the other two cases.

At the column removal connection, the reinforcement for the first and third floors encountered maximum compressive stresses $360 \mathrm{MPa}$. For the fifth floor, the top reinforcement didn't sustain any stress.
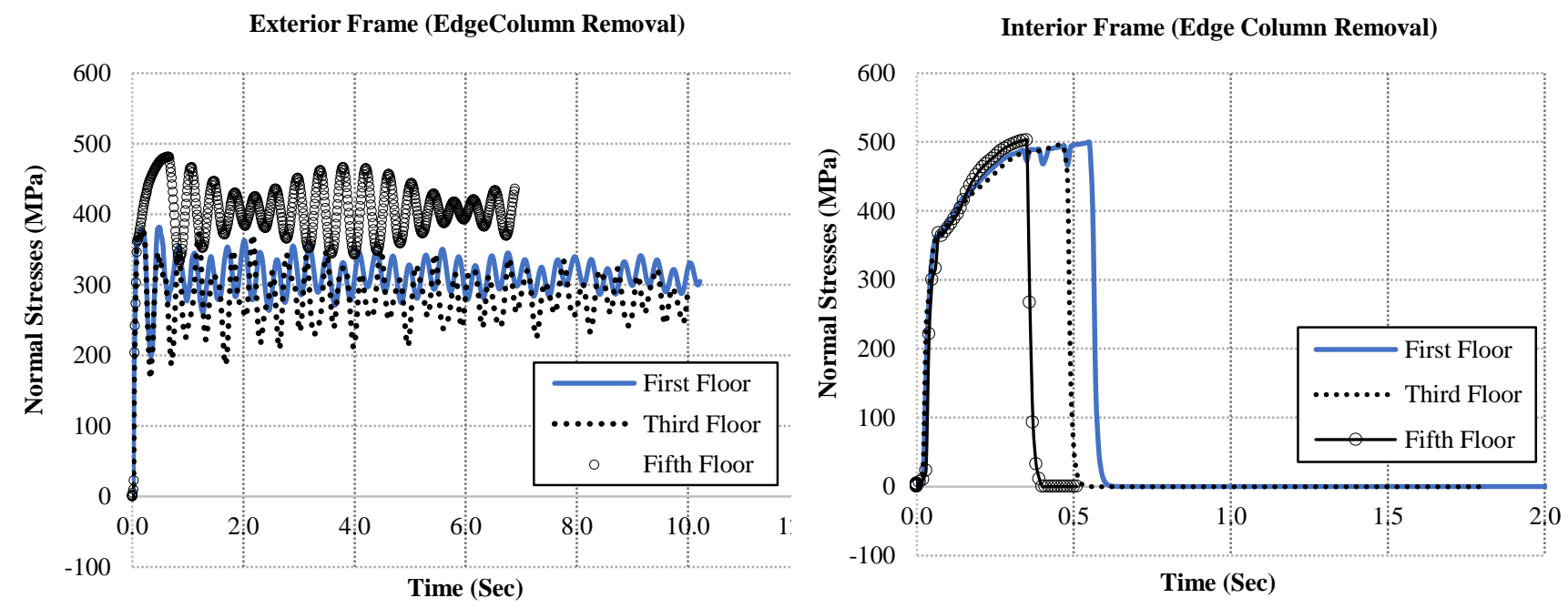

Figure 29. Normal Stresses in Top RFT versus Time at sides 


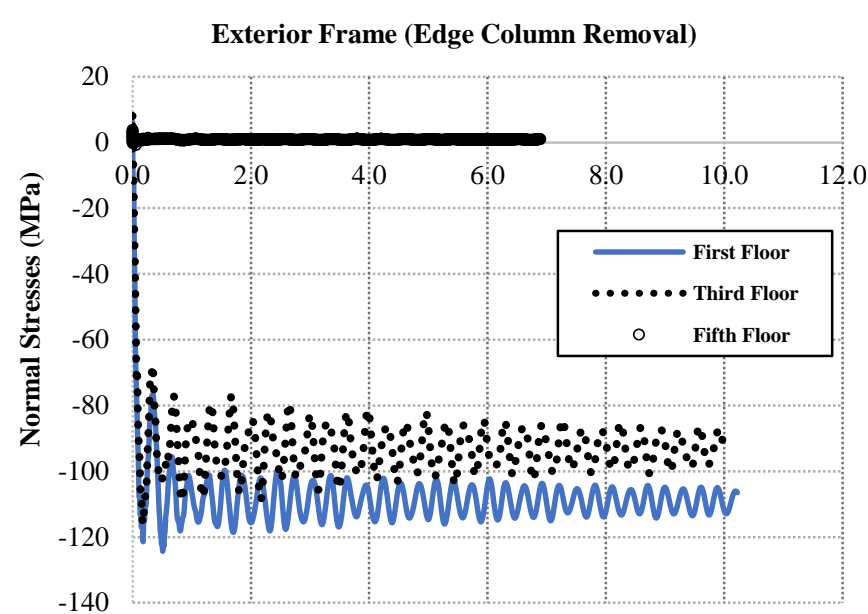

Time (Sec)

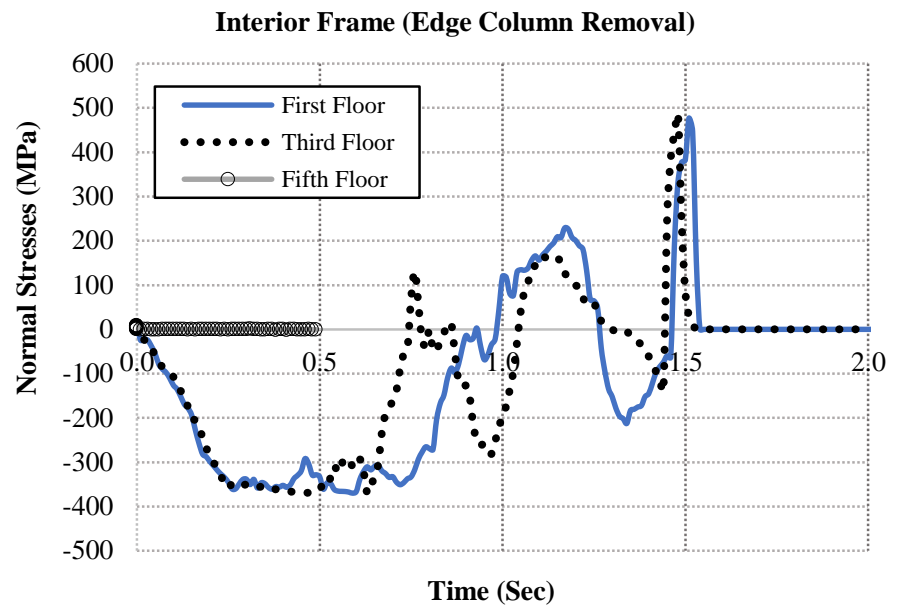

Figure 30. Normal Stresses in Top RFT versus Time at column Removal

\section{- Bottom Reinforcement}

The normal stresses in bottom reinforcement for both exterior and interior frames are calculated as shown in Figures 31 and 32. For the bottom reinforcement at the sides, the reinforcement encountered compressive stresses due to the applied negative bending moment on the connection. For the Exterior frame, the maximum stresses of $340 \mathrm{MPa}$ took place for the fifth floor and then stabilized. For the Interior frame, the bottom reinforcement failed for all cases with maximum stresses of $50 \mathrm{MPa}$.

At the column removal location, the bottom reinforcement of the Exterior frame reached maximum stresses of 350 $\mathrm{MPa}$ for the first-floor case. And for the Interior frame, the first and third-floor cases, the reinforcement rupture at the same time after reaching 490 MPa tensile stresses.

Exterior Frame (Edge Column Removal)

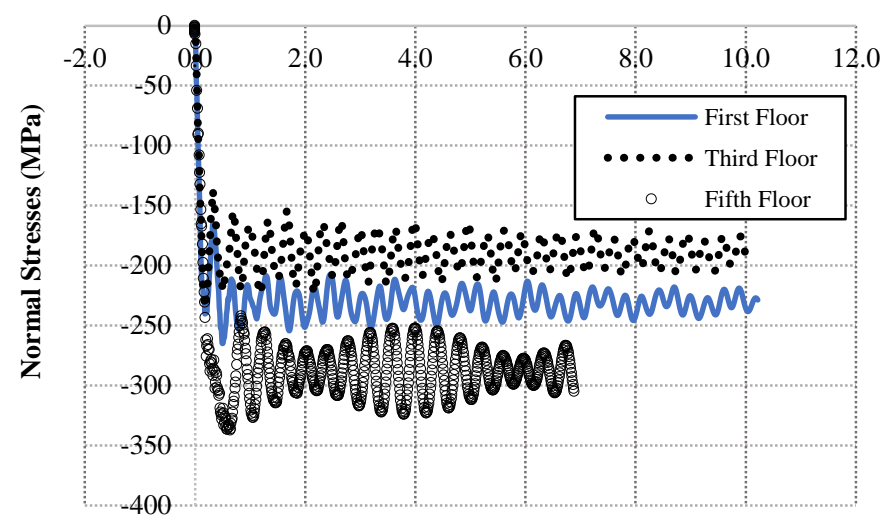

Time (Sec)

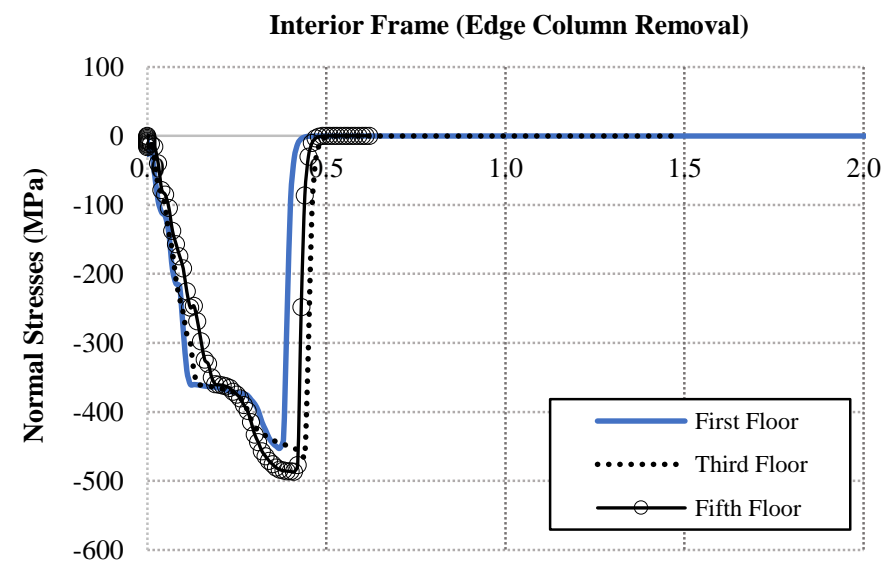

Time (Sec)

Figure 31. Normal Stresses in bottom RFT versus Time at sides
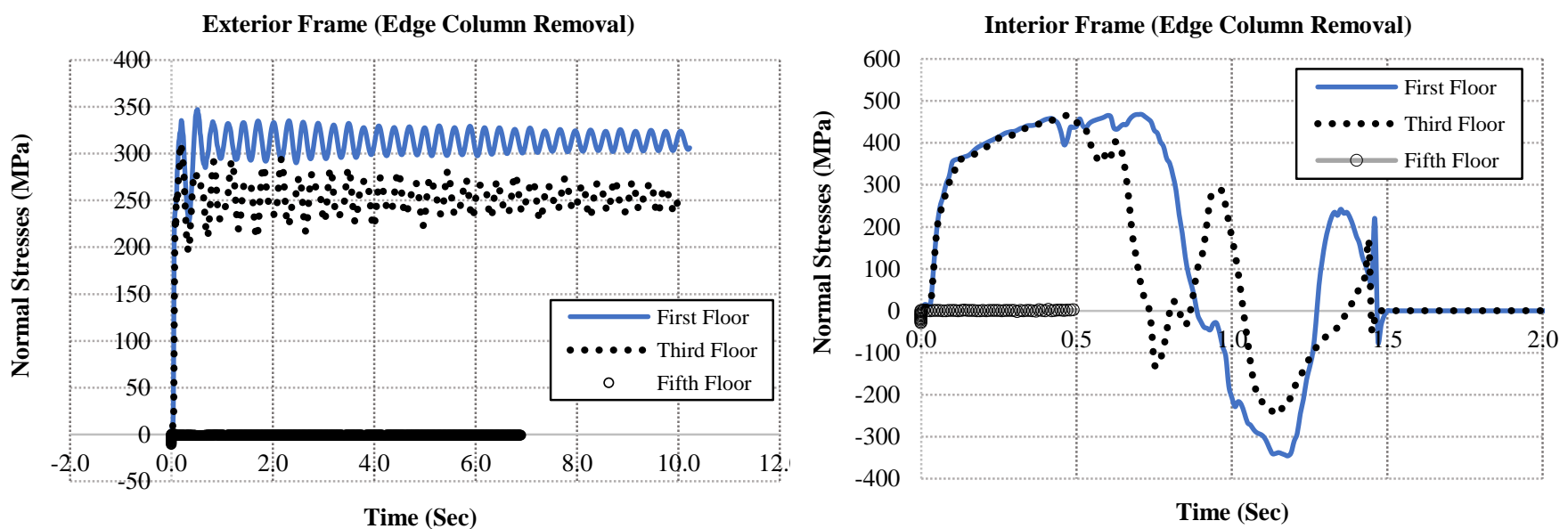

Figure 32. Normal Stresses in bottom Side RFT versus Time at Column Removal 


\section{Column axial forces and Rotations}

The percentage increase in axial force is calculated for the column in the middle span on the first floor. For the Exterior frame, the increase in the axial forces is $162 \%$ for the first-floor case, $100 \%$ for the third-floor case and $25 \%$ for the fifth floor. For the Interior frame, no increase is calculated due to its collapse. Column rotations are calculated for the Exterior frame case, and all cases met the UFC rotation limits.

\section{Conclusion}

Since the codes and regulations are not concerned about the connection behavior but the whole structural response, an investigation is conducted on special moment Column-Girder connection behavior, monolithically cast, against different column removal scenarios. The case study adopted is studied in detail. The failure pattern, internal stresses for the reinforcement, deflection of the main structural elements and internal forces in beams, columns and beam-column connection are extracted, and the following is concluded:

For the Exterior frame, no collapse is encountered due to many parameters. The frame location and load application are one of the main parameters that affected the frame behavior. The Vierendeel action effect in the first and third-floor cases is recognized compared to the fifth-floor case; this took place in the deflection of the girder as well as the normal stresses in the top and bottom reinforcement. The connection shear capacity specified by the ACI, which is already considered in the design, proved to resist the applied shear forces resulting from the redistribution of forces due to the column removal. Besides all this, there is a frame action that took place in cases of the third and fifth floors. The girders under the removed column floor worked as a tie member in resisting the lateral displacement caused by the compression arching phenomenon.

For the Interior frame, the applied loads are heavier compared to the Exterior frame. The failure is initiated by shear failure due to a high shear force followed by a rupture in the top reinforcement in the connections at the sides of the removed column. No collapse took place in the fifth-floor case, this is explained due to the absence of the effect of the upper floor that increased the applied loads on the 20-meter girder span.

For the edge column removal scenario, the girder acted as a cantilever with a span of 10 meters after the removal.

For the Exterior frame, the loads affected the frame behavior. No collapse occurred. The design nature of the frame leads the girder at the removal location to act as a broken frame girder with the upper column. This behavior took place due to the design nature of the Special moment connections that allowed the cantilever girder to work with the upper column as one unit. This redistribution along with the Vierendeel action helped to resist failure due to column loss.

For the Interior frame, the failure took place due to the heavy loads along with the cantilever action of the beam. The main cause of the failure is the high bending moment resulted from column removal. The Vierendeel action played a role in increasing the resistance of the structural components in resisting the failure in the first and the third-floor cases on the contrary to the fifth floor.

As a result, special moment connection could resist the column removal under light loading conditions; however, when the loads increase, some design considerations need to be suggested to resist either the excessive shear forces/ bending moment to contribute with the other parameters that helped to withstand the failure in Exterior frame case. Experimental testing is not enough to study the structural behavior due to column loss due to the different parameters that are very difficult in measuring and controlling in the laboratories compared to the numerical methods used. 3D modeling and structure testing under column removal scenarios is a must, to study the structural integrity in all directions and to give a real indication on the structure behavior in progressive collapse.

\section{Funding}

This work was supported and funded by the British University in Egypt [Young Investigator Research Grant (YIRG)]. The Project ID is YIRG2017-04.

\section{Conflicts of Interest}

The authors declare no conflict of interest.

\section{References}

[1] Guo, Lanhui, Shan Gao, and Feng Fu. "Structural Performance of Semi-Rigid Composite Frame under Column Loss." Engineering Structures 95 (July 2015): 112-126. doi:10.1016/j.engstruct.2015.03.049.

[2] Li, Menglu, and Mehrdad Sasani. "Integrity and Progressive Collapse Resistance of RC Structures with Ordinary and Special Moment Frames.” Engineering Structures 95 (July 2015): 71-79. doi:10.1016/j.engstruct.2015.03.050. 
[3] Weng, Jian, Chi King Lee, Kang Hai Tan, and Namyo Salim Lim. "Damage Assessment for Reinforced Concrete Frames Subject to Progressive Collapse.” Engineering Structures 149 (October 2017): 147-160. doi:10.1016/j.engstruct.2016.07.038.

[4] Dinu, Florea, Ioan Marginean, and Dan Dubina. "Experimental Testing and Numerical Modelling of Steel Moment-Frame Connections under Column Loss.” Engineering Structures 151 (November 2017): 861-878. doi:10.1016/j.engstruct.2017.08.068.

[5] Li, Honghao, Xianghui Cai, Lei Zhang, Boyi Zhang, and Wei Wang. "Progressive Collapse of Steel Moment-Resisting Frame Subjected to Loss of Interior Column: Experimental Tests." Engineering Structures 150 (November 2017): $203-220$. doi:10.1016/j.engstruct.2017.07.051.

[6] Arshian, Amir Hossein, and Guido Morgenthal. "Three-Dimensional Progressive Collapse Analysis of Reinforced Concrete Frame Structures Subjected to Sequential Column Removal.” Engineering Structures 132 (February 2017): 87-97. doi:10.1016/j.engstruct.2016.11.018.

[7] Behnam, Hamdolah, J.S. Kuang, and Roy Y.C. Huang. "Exterior RC Wide Beam-Column Connections: Effect of Beam Width Ratio on Seismic Behaviour.” Engineering Structures 147 (September 2017): 27-44. doi:10.1016/j.engstruct.2017.05.044.

[8] Lu, Xinzheng, Kaiqi Lin, Yi Li, Hong Guan, Peiqi Ren, and Yulong Zhou. "Experimental Investigation of RC Beam-Slab Substructures against Progressive Collapse Subject to an Edge-Column-Removal Scenario." Engineering Structures 149 (October 2017): 91-103. doi:10.1016/j.engstruct.2016.07.039.

[9] Pham, Anh Tuan, Kang Hai Tan, and Jun Yu. "Numerical Investigations on Static and Dynamic Responses of Reinforced Concrete Sub-Assemblages under Progressive Collapse." Engineering Structures 149 (October 2017): 2-20. doi:10.1016/j.engstruct.2016.07.042.

[10] Z. Li, , Y. Liu, J. Huo, H. Rong, J. Chen, A. Elghazouli. 2018. "Experimental assessment of fire-exposed RC beam-column connections with varying reinforcement development lengths subjected to column removal." Fire Saf. Journal 99 (2018) : 38 48. doi:10.1016/j.firesaf.2018.06.003.

[11] Al-Salloum, Yousef A., Mohammed A. Alrubaidi, Hussein M. Elsanadedy, Tarek H. Almusallam, and Rizwan A. Iqbal. "Strengthening of Precast RC Beam-Column Connections for Progressive Collapse Mitigation Using Bolted Steel Plates." Engineering Structures 161 (April 2018): 146-160. doi:10.1016/j.engstruct.2018.02.009.

[12] Qian, Kai, Shi-Lin Liang, Feng Fu, and Qin Fang. "Progressive Collapse Resistance of Precast Concrete Beam-Column SubAssemblages with High-Performance Dry Connections." Engineering Structures 198 (November 2019): 109552. doi:10.1016/j.engstruct.2019.109552.

[13] Tang, Hongyuan, Xuezhi Deng, Yigang Jia, Jingang Xiong, and Chunmei Peng. "Study on the Progressive Collapse Behavior of Fully Bolted RCS Beam-to-Column Connections." Engineering Structures 199 (November 2019): 109618. doi:10.1016/j.engstruct.2019.109618.

[14] Elsanadedy, Hussein M., Yousef A. Al-Salloum, Tarek H. Almusallam, Tuan Ngo, and Husain Abbas. "Assessment of Progressive Collapse Potential of Special Moment Resisting RC Frames - Experimental and FE Study.” Engineering Failure Analysis 105 (November 2019): 896-918. doi:10.1016/j.engfailanal.2019.07.045.

[15] Extreme Loading for Structures - Nonlinear Structural Analysis Software. Available online: https://www.extremeloading.com/ (accessed March 24, 2019).

[16] Tagel-Din, Hatem, and Kimiro Meguro. "Applied Element Method for simulation of nonlinear materials: theory and application for RC structures." Structural Eng./Earthquake Eng., International Journal of the Japan Society of Civil Engineers (JSCE) Vol 17 (2000): 137-148.

[17] Meguro, Kimiro, and Hatem Tagel-Din. "Applied element method for structural analysis: Theory and application for linear materials." Structural Engineering Earthquake Engineering 17, no. 1 (2000): 21-35.

[18] Meguro, Kimiro, and Hatem Tagel-Din. "Applied element simulation of RC structures under cyclic loading." Journal of Structural Engineering 127, no. 11 (2001): 1295-1305. doi: 10.1061/(ASCE)0733-9445(2001)127:11(1295).

[19] Maekawa, K., and H. Okamura. "The deformational behavior and constitutive equation of concrete using the elasto-plastic and fracture model." Journal of the Faculty of Engineering. University of Tokyo. Series B 37, no. 2 (1983): 253-328.

[20] B. K., Solution of equilibrium equations in dynamic analysis, Prentice Hall, Englewoods Cliffs, N.J, 1982.

[21] Chopra, Anil K. "Dynamics of Structures: Theory and Applications to Earthquake Engineering, Prentice Hall." Inc., Upper Saddle River, NJ (1995).

[22] ACI Committee. "Building code requirements for structural concrete (ACI 318-05) and commentary (ACI 318R-05)." American Concrete Institute, 2005.

[23] Department of Defense (DoD), Unified Facilities Criteria (UFC) Design of Buildings to Resist Progressive Collapse Approved For Public Release; Distribution Unlimited, 2009. 